\title{
Método de determinação da margem de contribuição de produtos com variabilidade de preços e custos diretos unitários: Uma aplicação em uma indústria de produtos plásticos
}

\begin{abstract}
Abraão Freires Saraiva Junior Mestrado em andamento em Engenharia de Produção pela Universidade de São Paulo - USP Av. Prof. Almeida Prado - Tr. oㅡ 2, 128. Cidade Universitária. São Paulo/SP. CEP: 05508-070 E-mail: abraaofsjr@gmail.com

Maxweel Veras Rodrigues Doutorado em Engenharia de Produção pela Universidade Federal de Santa Catarina UFSC Professor da Universidade Federal do Ceará - UFC Centro de Tecnologia da UFC, Bloco 714. Fortaleza/CE. CEP: 60455-760

E-mail:maxweelveras@gmail.com

Reinaldo Pacheco da Costa Doutorado em Engenharia de Produção pela Universidade de São Paulo - USP Professor da Universidade de São Paulo - USP Av. Prof. Almeida Prado, 128, Sala 206. Cidade Universitária. São Paulo/SP. CEP: 05508-900 E-mail:rpcosta@usp.br
\end{abstract}

\section{RESUMO}

O presente artigo objetiva apresentar um método para determinar a margem de contribuição de produtos que possuem acentuada variabilidade de custos diretos unitários e de receitas unitárias. Para cumprir este objetivo, é proposto um método de três etapas que é construído a partir da integração de técnicas provindas da Contabilidade Gerencial e da Pesquisa Operacional, com destaque à simulação de Monte Carlo. O método é aplicado a partir de um exemplo didático que utiliza dados reais obtidos por meio de uma pesquisa realizada em uma indústria brasileira de produtos plásticos que utiliza material reciclado. Conclui-se que o método é eficaz no tratamento da variabilidade de preços e custos diretos unitários para a determinação da margem de contribuição de produtos.

Palavras-chave: Variabilidade de custos diretos unitários e de preços. Simulação de Monte Carlo. Margem de contribuição. 
Método de determinação da margem de contribuição de produtos com variabilidade de preços e custos diretos unitários: Uma aplicação em uma indústria de produtos plásticos Abraão Freires Saraiva Junior, Maxweel Veras Rodrigues, Reinaldo Pacheco da Costa

\title{
Method for determining the contribuition margin of products with prices and direct costs per unit variability: an application in a plastic products factory
}

\begin{abstract}
The aim is to present a method to determine the contribution margin of products that have marked direct costs per unit and prices variability. To achieve this goal, is proposed a three-step method built from the integration of Management Accounting and Operations Research techniques, emphasizing the Monte Carlo simulation. The method is applied from a didactic example which uses real data achieved through a research carried out in a plastic products industry that employ recycled material. Finally, it is concluded that the method is effective in the treatment of variability in prices and direct costs per unit in order to determine the products contribution margin.
\end{abstract}

Key Words: Prices and direct costs per unit variability. Monte Carlo simulation. Contribution margin.

\section{INTRODUÇÃO}

A abertura de mercado e o rápido desenvolvimento de novas tecnologias têm impactado de maneira decisiva as organizações, fazendo-as buscar novas metodologias de gestão que as tornem mais competitivas. Não existe mais privilégio por ser uma pequena ou grande empresa, todas estão no mesmo mercado competindo pelos mesmos clientes. Os gestores precisam conhecer bem os custos, saber tomar decisões, utilizar de forma sistêmica as informações, entender o cliente e conseguir atingir o mercado e suas necessidades. Uma análise criteriosa de variáveis como os preços e custos que compõem um produto pode ser utilizada como arma competitiva, a fim de melhor satisfazer a estratégia e o processo de consolidação e crescimento de uma empresa (LEONE, 2000).

Uma adequada compreensão destas variáveis auxilia na definição de métricas ou parâmetros de decisão que podem ser utilizados na melhoria do resultado econômico da empresa. Um dos parâmetros de decisão existente é a margem de contribuição, que possui mensuração econômica (PADOVEZE, 2006).

Em alguns processos de produção, o levantamento e análise de custos são 
Método de determinação da margem de contribuição de produtos com variabilidade de preços e custos diretos unitários: Uma aplicação em uma indústria de produtos plásticos Abraão Freires Saraiva Junior, Maxweel Veras Rodrigues, Reinaldo Pacheco da Costa

dificultados devido à existência de produtos que possuem elevada variabilidade de utilização de matérias-primas e de outros recursos. Tem-se, como exemplo, a indústria de fabricação de produtos plásticos a partir de materiais reciclados, em que se observa uma considerável variação dos custos diretos unitários, variação esta ocasionada pela alternância da quantidade de material e tempo de processamento demandados por produto.

Dentro desse contexto, levanta-se o seguinte questionamento que baliza o estudo: como determinar a margem de contribuição unitária de produtos que possuem acentuada variabilidade de custos diretos unitários e de preços de venda? Para responder a esse questionamento, no presente estudo fez-se o uso de técnicas provindas da Contabilidade Gerencial e da Pesquisa Operacional, com destaque ao método de simulação de Monte Carlo.

O artigo é estruturado a partir da fundamentação teórica, em que é apresentado o conceito de margem de contribuição e os aspectos inerentes à simulação com destaque ao método de Monte Carlo. Na metodologia, são enfatizadas as etapas da pesquisa. Em seguida, é apresentado o método proposto para determinar a margem de contribuição unitária dos produtos (esperada para um determinado período) em um cenário de variabilidade de custos unitários. Na seqüência, é apresentada uma aplicação do método proposto a partir de um exemplo didático que utiliza dados coletados em uma indústria real, bem como os resultados alcançados. Na última seção é exposta a conclusão do estudo.

\section{REFERENCIAL TEÓRICO}

\subsection{Margem de contribuição}

Para que se compreenda o conceito da Margem de Contribuição é preciso, primeiramente, que se entenda a abordagem do Método de Custeio Variável (MCV). Martins (2006, p. 198) argumenta que "no MCV, somente os custos variáveis são alocados aos produtos, ficando os fixos separados e considerados como despesas do período, indo diretamente para o resultado". Também chamado por alguns autores de 
Método de determinação da margem de contribuição de produtos com variabilidade de preços e custos diretos unitários: Uma aplicação em uma indústria de produtos plásticos Abraão Freires Saraiva Junior, Maxweel Veras Rodrigues, Reinaldo Pacheco da Costa

custeio direto (ex: FOSTER; BAXENDALE, 2008), o MCV, ao identificar os custos de comportamento variável, permite uma análise gerencial em função do grau de participação de cada componente de custo no valor global do objeto de custo (produtos, pedidos, clientes, segmentos da empresa, entre outros) trazendo conclusões objetivas do ponto de vista gerencial (GARRISON et al., 2006). Embora seja utilizado para fins de tomada de decisões gerenciais, o MCV não é adequado em relação à legislação e às normas contábeis e fiscais brasileiras (BRUNI, 2006).

Derivada do custeamento variável, a Margem de Contribuição (MC) é caracterizada pela diferença entre a receita e a soma de custos e despesas variáveis, fazendo com que seja evidenciado o valor que cada unidade produzida, linha de produto, pedido ou cliente proporciona de sobra à empresa entre a sua receita e o custo que de fato tenha provocado (MARTINS, 2006). Os custos fixos são subtraídos da margem de contribuição para se obter o lucro operacional líquido da empresa em um determinado período. Convém ressaltar que há divergências sobre a classificação da mão-de-obra como custo variável. Por exemplo, Guerreiro (2006) considera a mão-deobra direta como um recurso com custo de comportamento fixo. A Figura 1 apresenta, esquematicamente, o modelo conceitual do método de custeio variável com o cálculo da margem de contribuição: 
Método de determinação da margem de contribuição de produtos com variabilidade de preços e custos diretos unitários: Uma aplicação em uma indústria de produtos plásticos Abraão Freires Saraiva Junior, Maxweel Veras Rodrigues, Reinaldo Pacheco da Costa

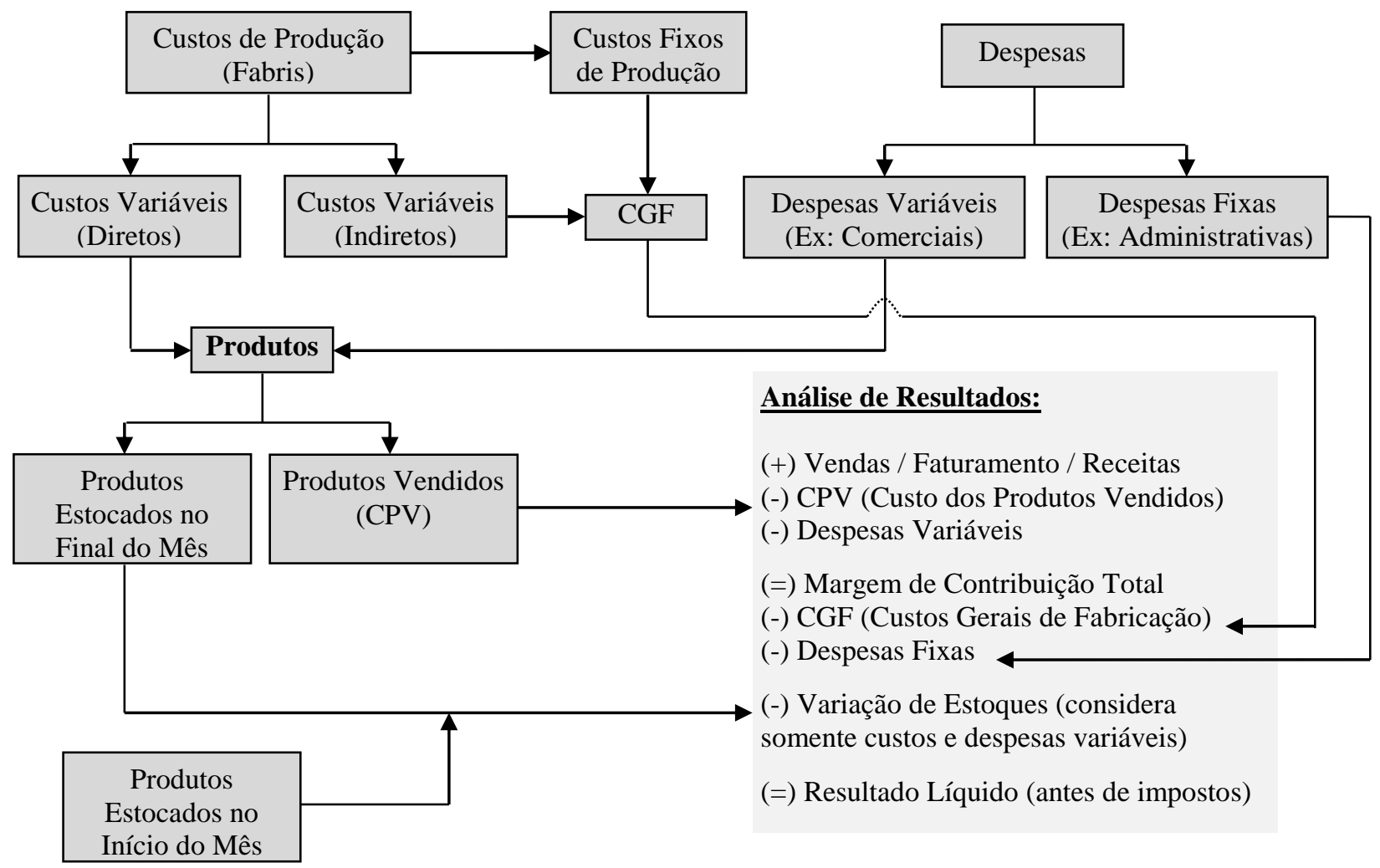

Figura 1: Modelo conceitual do custeio variável com análise de resultados por margem de contribuição Fonte: Adaptado de Costa (1998).

A MC propicia informações ao gerente para decidir se é coerente diminuir ou expandir uma linha de produção, para avaliar as alternativas provenientes do mix de produção e venda e de propagandas especiais, para verificar se é economicamente interessante aceitar um pedido ou não, além de verificar quais produtos, pedidos e clientes são mais lucrativos para a empresa (ASSEF, 2005). Quando a unidade de mensuração é uma unidade de produto produzido e vendido, tem-se a Margem de Contribuição Unitária (MCU) do produto. Ressalta-se que, em alguns processos, a MCU do produto sofre variação. Esta decorre da variabilidade dos itens que a compõem, itens estes apontados por Padoveze (2006) como: custos diretos unitários de material, de mão-de-obra e de utilidades (energia, água, ar-comprimido, entre outros); despesas variáveis unitárias (comissões de venda, frete de entrega, entre outros); e preços de venda do produto. 
Método de determinação da margem de contribuição de produtos com variabilidade de preços e custos diretos unitários: Uma aplicação em uma indústria de produtos plásticos Abraão Freires Saraiva Junior, Maxweel Veras Rodrigues, Reinaldo Pacheco da Costa

\subsection{Simulação}

Inserida no campo de conhecimento da Pesquisa Operacional, a simulação é uma imitação da operação de um processo ou sistema real, num dado período de tempo, que envolve a geração de uma história artificial desse sistema e a observação desta para fazer inferências relativas às características do processo real (BANKS et al., 1996). Hillier e Lieberman (2005) indicam que o primeiro passo para a realização de uma simulação é o desenvolvimento de um modelo que represente o sistema a ser investigado, modelo este que, no entendimento de Pidd (1998), consiste em uma representação explícita e externa de um extrato parcial da realidade vista pela pessoa que deseja usar um modelo para entender, mudar, gerenciar, indicar políticas e controlar parte daquela realidade.

Convém ressaltar que, apesar de um modelo ser uma representação simplificada de um sistema ou realidade em estudo, este deve conter detalhamento suficiente para que possa ser utilizado como uma representação válida (BANKS et al., 1996). A simulação tem sido utilizada na engenharia para designar situações nas quais se tenta compreender características de um sistema pelo conhecimento de outro que é similar (PRADO, 2004), sendo especialmente útil em situações que envolvem análise de riscos (LUSTOSA et al., 2004).

A simulação possui dependência com o tipo de variável a ser considerada no modelo. Winston (1994) e Law e Kelton (2000) consideram que existem dois tipos de simulação: (i) de eventos discretos; e (ii) de eventos contínuos. Sakurada e Miyake (2009, p. 26) fazem uma descrição sucinta dos dois tipos de simulação, argumentando que

A simulação de eventos discretos abrange o estudo de modelos de simulação cujas variáveis mudam de estado instantaneamente em pontos específicos de tempo, em contraste ao que ocorre com modelos contínuos, cujas variáveis podem mudar de estado continuamente no decorrer do tempo.

No entendimento de Borshchev e Filippov (2004), simulações de eventos discretos abrangem sistemas com médio a alto nível de detalhamento, sendo geralmente aplicadas para modelagem de sistemas com níveis mais baixos de 
Método de determinação da margem de contribuição de produtos com variabilidade de preços e custos diretos unitários: Uma aplicação em uma indústria de produtos plásticos Abraão Freires Saraiva Junior, Maxweel Veras Rodrigues, Reinaldo Pacheco da Costa

abstração (ex: cadeia de suprimento, chão de fábrica e call center), ao passo que simulações de eventos contínuos, tais como as baseadas na Dinâmica de Sistemas (FORRESTER, 1961), são utilizadas em modelagem de sistemas agregados com níveis mais altos de abstração (ex: dinâmicas populacionais e controle de doenças).

Buffa (1973) e Winston (1994) sugerem que uma forma de simular um sistema, considerando o comportamento do tipo de variáveis que se pretende analisar, é através do desenvolvimento de um modelo de simulação utilizando distribuições de freqüência de eventos discretos, conhecido como método simulação de Monte Carlo, descrito a seguir.

\subsection{Método de simulação de Monte Carlo}

A simulação Monte Carlo envolve o uso de números aleatórios e probabilidades para resolver problemas. Este médoto surgiu no Projeto Manhattan do laboratório de armas nucleares Los Alamos, Estados Unidos, no início da década de 1940 durante a Segunda Guerra Mundial, sendo desenvolvido pelos cientistas John Von Neumann e Stanislaw Ulam. A denominação "Monte Carlo" foi cunhada em referência aos jogos de azar que fazem uso constante de sorteios e de dados, uma atração popular na cidade de Monte Carlo, no principado de Mônaco (METROPOLIS; ULAM, 1949, METROPOLIS, 1987).

No entendimento de Lustosa et al. (2004, p. 251), a simulação de Monte Carlo (SMC) consiste em um método que "utiliza a geração de números aleatórios para atribuir valores às variáveis do sistema que se deseja investigar. " Os números podem ser obtidos através de algum processo aleatório (ex: tabelas, roletas e sorteios) ou diretamente de softwares, através de funções específicas (para obter mais detalhes sobre métodos de obtenção de números aleatórios, consultar Gentle (2003)). A cada iteração, o resultado é armazenado e, ao final de todas as iterações, a seqüência de resultados gerados é transformada em uma distribuição de freqüência que possibilita calcular estatísticas descritivas, como a média (valor esperado), valor mínimo, valor máximo e o desvio-padrão, cabendo ainda ao executor das simulações a prerrogativa de projetar cenários futuros de operação do sistema em análise. 
Método de determinação da margem de contribuição de produtos com variabilidade de preços e custos diretos unitários: Uma aplicação em uma indústria de produtos plásticos Abraão Freires Saraiva Junior, Maxweel Veras Rodrigues, Reinaldo Pacheco da Costa

O método de simulação de Monte Carlo possui aplicações em problemas de tomada de decisão que envolve riscos, ou seja, situações nas quais o comportamento de um ou mais fatores (variáveis envolvidas com o problema) não são de natureza determinística. Neste caso, estes fatores são caracterizados por um comportamento probabilístico e podem ser trabalhados a partir da simulação de Monte Carlo (LUSTOSA et al., 2004). Para operacionalizar a SMC, Shamblin e Stevens (1974) recomendam que alguns passos básicos sejam seguidos, como mostra a Figura 2:

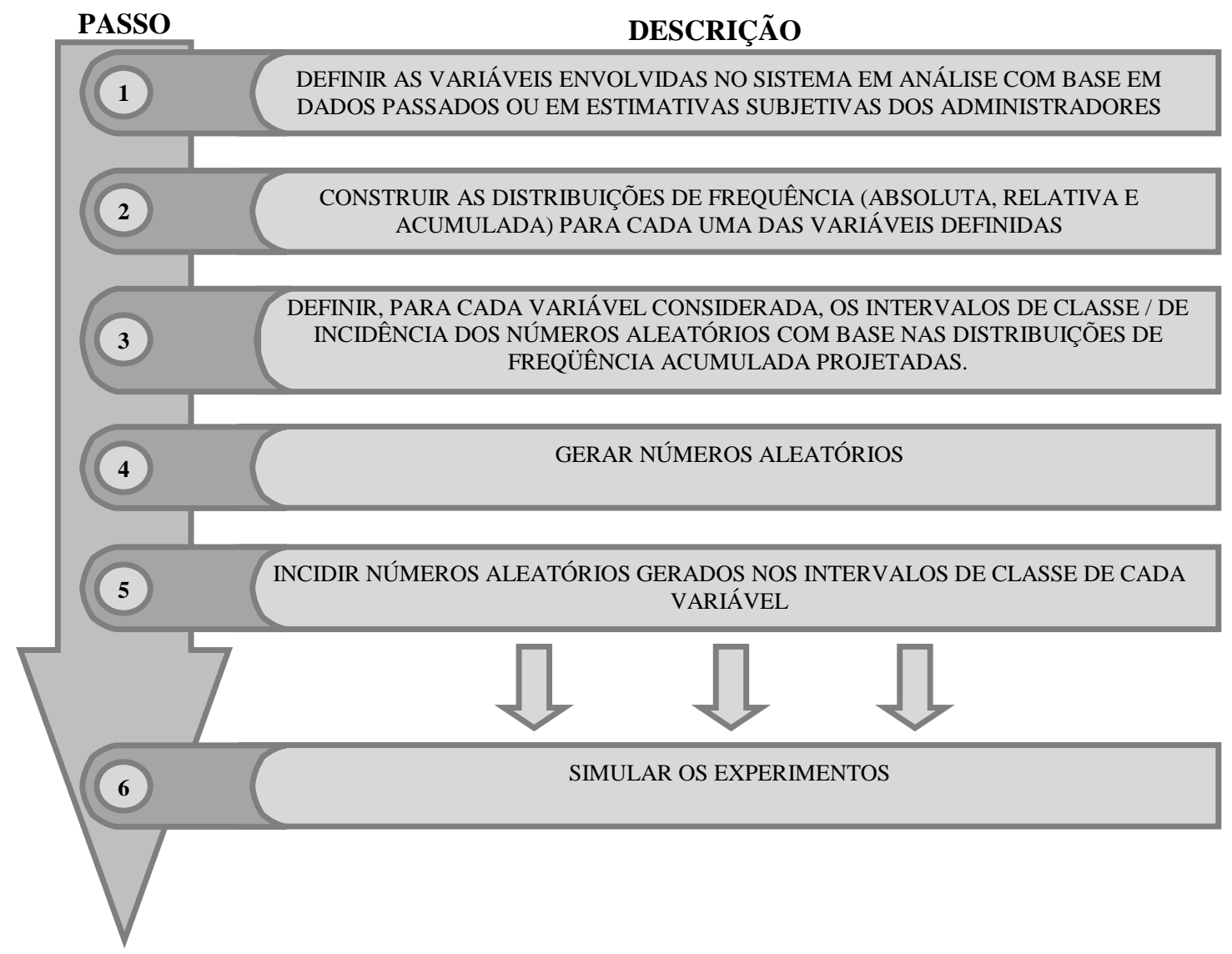

Figura 2: Passos para operacionalização do método de simulação de Monte Carlo Fonte: Adaptado de Shamblin e Stevens (1974).

Para uma correta operacionalização da SMC, Lustosa et al. (2004) indicam que a simulação deve ser replicada mais de cem vezes para que se obtenha uma amostra representativa. No entanto, não há recomendação quanto ao número máximo de 
Método de determinação da margem de contribuição de produtos com variabilidade de preços e custos diretos unitários: Uma aplicação em uma indústria de produtos plásticos Abraão Freires Saraiva Junior, Maxweel Veras Rodrigues, Reinaldo Pacheco da Costa

simulações a serem realizadas, pois este número depende da capacidade de processamento do equipamento utilizado para executar as simulações. Como instrução básica, deve-se aplicar o maior número de simulações possíveis levando em consideração o poder de processamento do equipamento a ser utilizado, pois o equilíbrio entre precisão e tempo de computação é uma característica importante das simulações baseadas no método de Monte Carlo.

\section{METODOLOGIA}

Para responder à pergunta de pesquisa proposta, o presente estudo foi desenvolvido em três momentos: (i) revisão bibliográfica; (ii) proposição de um método; e (iii) aplicação do método proposto a partir de um exemplo didático que utiliza dados reais obtidos através de uma pesquisa de campo.

Com o intuito de encontrar conceitos, teorias e técnicas que fundamentassem a construção de uma resposta para a pergunta de pesquisa, foi realizada uma (i) revisão bibliográfica que, de acordo com Gil (2002, p. 44), "é desenvolvida com base em material já elaborado, constituído principalmente de livros e artigos [...]”. Primeiramente, a revisão bibliográfica envolveu a busca de publicações, no campo da Contabilidade Gerencial, sobre a métrica de mensuração econômica: Margem de Contribuição. Em seguida, foram buscadas, no campo da Pesquisa Operacional, publicações que versassem sobre técnicas quantitativas que compreendessem 0 tratamento de variabilidade e que pudessem ser trabalhadas de forma integrada com a métrica investigada inicialmente na revisão bibliográfica.

De posse do arcabouço teórico prospectado, a questão de pesquisa passou a ser trabalhada metodologicamente a partir da (ii) proposição de um método para auxiliar a determinação da margem de contribuição unitária dos produtos. O método constituise de três etapas organizadas de forma seqüencial e compostas de expressões matemáticas.

Em seguida, o método proposto foi aplicado em um processo produtivo a partir de um exemplo didático que foi respaldado por uma (iii) pesquisa realizada em uma 
Método de determinação da margem de contribuição de produtos com variabilidade de preços e custos diretos unitários: Uma aplicação em uma indústria de produtos plásticos Abraão Freires Saraiva Junior, Maxweel Veras Rodrigues, Reinaldo Pacheco da Costa

indústria brasileira de artefatos plásticos. Conforme Marconi e Lakatos (2008, p. 188), uma pesquisa realizada no campo, in loco, "consiste na observação de fatos e fenômenos tal como ocorrem espontaneamente, na coleta de dados a eles referentes e no registro de variáveis que se presumem relevantes, para analisá-los". Desta forma, foram realizadas entrevistas com pessoas-chave na empresa e coletados dados e informações para obtenção de elementos reais relativos ao processo produtivo, à estrutura de produto, aos gastos e aos preços de venda praticados. As principais fontes de evidência coletadas na pesquisa (adaptando os termos de Yin (2005), voltados para o planejamento de estudos de caso) são apresentadas no Quadro 1:

\begin{tabular}{|c|c|}
\hline $\begin{array}{c}\text { FONTE DE } \\
\text { EVIDÊNCIAS }\end{array}$ & $\begin{array}{c}\text { PRINCIPAIS ELEMENTOS TRABALHADOS E MATERIAIS } \\
\text { COLETADOS }\end{array}$ \\
\hline Documentação & $\begin{array}{c}\text { - Memorial descritivo do processo produtivo da empresa } \\
\text { - Mapa de localização de custos } \\
\text { - Especificações técnicas de produtos e de equipamentos }\end{array}$ \\
\hline Registros em arquivos & $\begin{array}{c}\text { - Relatórios contábeis mensais } \\
\text { - Planilhas de centros de custos } \\
\text { - Contas de energia }\end{array}$ \\
\hline $\begin{array}{c}\text { Entrevistas } \\
\text { (semi-estruturadas) }\end{array}$ & $\begin{array}{c}\text { - Diretor Industrial } \\
\text { - Diretor Financeiro } \\
\text { - 2 supervisores de produção }\end{array}$ \\
\hline Observações diretas & - Responsável pela controladoria da empresa \\
\hline Observação participante & - Participação em 3 reuniões com os diretores da empresa \\
\hline Artefatos físicos & - Quadro com índices de refugo mensais \\
\hline
\end{tabular}

Quadro 1: Fontes de evidências coletadas na pesquisa in loco

Fonte: Elaborado pelo autor

Para completar o exemplo didático e inseri-lo no contexto da questão de pesquisa proposta, estabeleceu-se um cenário hipotético com a assunção de algumas suposições sobre o processo produtivo da empresa em estudo. Em seguida, dentro do cenário construído, as informações coletadas foram trabalhadas e apresentadas em planilhas eletrônicas para facilitar aplicação do método proposto e a visualização dos resultados alcançados. 
Método de determinação da margem de contribuição de produtos com variabilidade de preços e custos diretos unitários: Uma aplicação em uma indústria de produtos plásticos Abraão Freires Saraiva Junior, Maxweel Veras Rodrigues, Reinaldo Pacheco da Costa

\subsection{Método proposto}

Aqui é exposta a estrutura do método proposto para auxiliar o processo de determinação da margem de contribuição unitária de produtos que possuem acentuada variabilidade de custos diretos unitários e de receitas unitárias. O método é dividido em três etapas e utiliza dois corpus teóricos: a margem de contribuição unitária e a simulação de Monte Carlo.

A primeira etapa consiste na análise e projeção dos gastos unitários, ou seja, dos custos e despesas que incidem em cada produto da empresa, devendo ser minucioso e possuir uma base de dados confiável, pois tem influência direta nos resultados que se pretende obter. A segunda etapa corresponde à análise dos dados relativos aos preços de venda praticados pela empresa. A terceira etapa é a determinação da Margem de Contribuição Unitária Esperada (MCUE) dos produtos para o período em análise. A Figura 3 mostra, esquematicamente, a estrutura do modelo proposto:

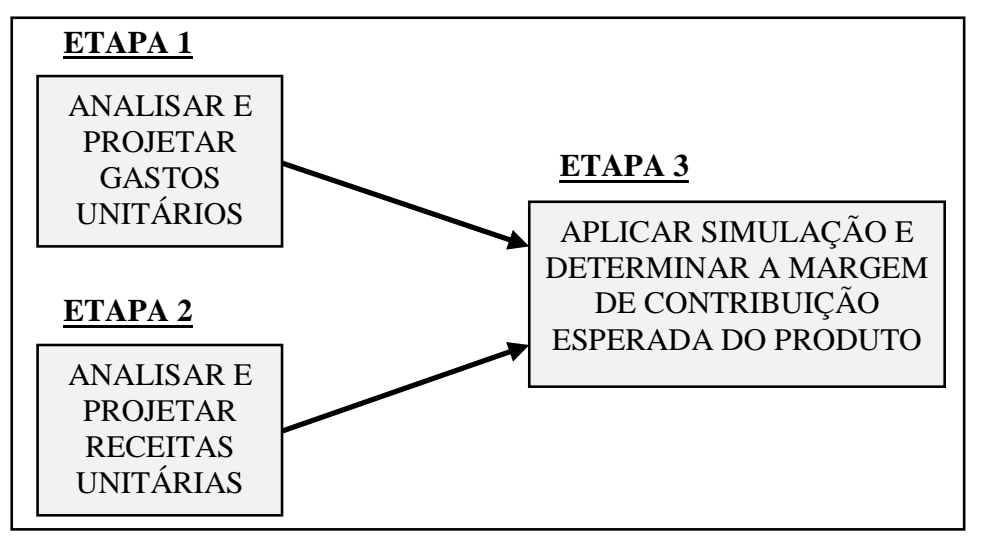

Figura 3: Estrutura do modelo proposto para determinação da Margem de Contribuição Unitária Esperada

As setas indicam as relações de dependência entre as etapas, ou seja, as informações que são necessárias para a realização de cada uma das etapas. Além disso, convém comentar que a variabilidade de custos diretos unitários pode ser ocasionada, por exemplo, pela má qualidade da matéria-prima que implica em uma variação do consumo de material e no tempo de fabricação de cada produto no decorrer de um determinado período de tempo. 
Método de determinação da margem de contribuição de produtos com variabilidade de preços e custos diretos unitários: Uma aplicação em uma indústria de produtos plásticos Abraão Freires Saraiva Junior, Maxweel Veras Rodrigues, Reinaldo Pacheco da Costa

\section{Etapa 1 - analisar e projetar gastos unitários}

Para que esta etapa seja concluída com êxito, a estrutura da empresa deve ser conhecida, incluindo o seu funcionamento, mão-de-obra utilizada, produtos fabricados, impostos incidentes, entre outros. A etapa 1 consiste no levantamento e análise de todos os custos e despesas que incidem diretamente nos produtos fornecidos pela empresa. Para análise destes custos e despesas, deve-se fazer uso de dados históricos de um horizonte temporal aceitável. Em seguida, é realizada uma avaliação da freqüência de incidência desses gastos a fim de projetá-los para o período em análise. Esta projeção é feita através da construção de histogramas de freqüência de utilização, por produto, de cada recurso produtivo. Vale ressaltar que para efeito do corrente estudo, são considerados apenas os gastos variáveis da empresa, pois os gastos fixos não têm influência direta na determinação da margem de contribuição.

Essas distribuições geradas constituem a base para aplicação da simulação a ser utilizada na determinação da MCUE dos produtos.

Para execução desta etapa, primeiramente, devem ser identificados os custos e despesas que variam diretamente com o volume de produção. A seguir, são apresentados os principais custos e despesas que podem ser classificados como variáveis, junto ao modo que estes devem ser analisados e projetados, conforme 0 método proposto:

- Material Direto: No caso em que o produto é feito a partir de uma mistura de matérias-prima (MP), deve-se levantar, em peso e em valor monetário, cada quantidade de MP utilizada. O levantamento do quantitativo de material consumido pode ser realizado a partir de pesagens de cada lote produzido. Davis et al. (1999) indicam que o tamanho da amostra a ser testada pode ser de cinco unidades, já que para aplicações industriais do controle de processo é preferível fazer o uso de amostras de tamanho pequeno. De posse dessas informações, calcula-se o custo da matéria-prima para cada produto, para cada lote em análise. Esses valores são projetados a partir de histogramas de freqüência e utilizados na determinação da margem de contribuição unitária do produto. Vale ressaltar que, no caso de um processo de industrialização, 
Método de determinação da margem de contribuição de produtos com variabilidade de preços e custos diretos unitários: Uma aplicação em uma indústria de produtos plásticos Abraão Freires Saraiva Junior, Maxweel Veras Rodrigues, Reinaldo Pacheco da Costa

impostos recuperáveis como ICMS, IPI, entre outros, não valoram os custos, pois são repassados ao consumidor final.

- Mão-de-obra Direta: consiste nos salários nominais mais os encargos sociais e benefícios dos funcionários diretamente relacionados com a fabricação dos produtos. A projeção desse tipo de custo também pressupõe uma base histórica de dados e é feita através de distribuição de freqüência. Como esse custo tem relação unívoca com o tempo de processamento destinado pelo operário para cada produto, e este tempo, normalmente, possui variabilidade, pode-se fazer o uso histogramas de freqüência para projetar esses custos unitários para períodos seguintes. Os custos inerentes ao pessoal de apoio à produção, como os supervisores, gerentes, mecânicos, inspetores, faxineiros, entre outros, não compõem a base de cálculo desse gasto, pois são classificados como Custos Indiretos de Fabricação (CIF) ou Custos Gerais de Fabricação (CGF).

- Utilidades: nos casos em que a fabricação de produtos pressupõe a utilização de maquinário e este é operacionalizado através de energia elétrica, deve-se determinar quanto cada produto custa em relação ao consumo energético. Ressalta-se que esse custo está diretamente ligado ao tempo utilizado da máquina ou equipamento para a fabricação de cada produto, aqui denominado Tempo de Ciclo (TC). Existem máquinas que medem, automaticamente, o tempo de ciclo para cada unidade produzida, além de oferecer um histórico das medições. Por motivos diversos, como a má qualidade da matéria-prima, por exemplo, verifica-se que esses tempos de processamento podem variar aleatoriamente. De forma similar aos itens anteriores, deve-se analisar o histórico de utilização das máquinas para cada produto. Em seguida, esses dados devem ser representados através de histogramas e projetados na forma de distribuição de freqüência. Vale ressaltar que outros itens consumidos pelo maquinário podem ser tratados de forma similar à energia, tais como: óleo lubrificante, fluido refrigerante, água, ar comprimido e gás natural. Para tal, basta que estes tenham sua utilização mensurada, relacionada à produção de cada produto e valorada em termos de custos unitários. 
Método de determinação da margem de contribuição de produtos com variabilidade de preços e custos diretos unitários: Uma aplicação em uma indústria de produtos plásticos Abraão Freires Saraiva Junior, Maxweel Veras Rodrigues, Reinaldo Pacheco da Costa

- Despesas Variáveis: mesmo não relacionadas diretamente com o processo produtivo em si, as despesas variáveis variam com o volume de produtos vendidos e têm influência direta na determinação da MCU. Bernardi (2004) destaca, como principais despesas variáveis, os gastos relacionados com comissões sobre vendas, com a distribuição de produtos, entre outros.

Em suma, o output esperado desta etapa é a projeção das distribuições de freqüência de utilização de cada recurso em cada produto, junto aos valores monetários correlacionados. Para tal, pode-se fazer o uso de softwares como o MINITAB® 15.0 e o EXCEL® 2007. Para a determinação da MCU são necessárias, ainda, informações referentes às receitas unitárias. Estas são tratadas a seguir.

\section{Etapa 2 - analisar e projetar receitas unitárias}

Nesta etapa são analisadas e projetadas as receitas unitárias dos produtos. Como as receitas unitárias referem-se aos preços de venda praticados, esta etapa delineia-se apenas na análise de dados históricos relativos ao valor venal de cada produto. Vale ressaltar que, em muitas empresas, os preços são tabelados levando em consideração tanto fatores mercadológicos (práticas da concorrência, por exemplo), como também fatores econômicos (inflação e o aumento da tributação, por exemplo). Convém lembrar que, no âmbito deste estudo para fins gerenciais, o preço unitário de venda refere-se ao preço à vista e não considera o Imposto sobre Produtos Industrializados (IPI), Imposto sobre Circulação de Mercadorias e Serviços (ICMS) ou qualquer outro tributo que incide sobre a venda.

De posse dessas informações, são construídos histogramas e realizam-se projeções na forma de distribuições de freqüência. Estas projeções são aproveitadas, através de simulação, na determinação da MCU de cada produto que a empresa fornece.

\section{Etapa 3 - aplicar simulação e determinar a margem de contribuição unitária esperada do produto}

Esta etapa consiste na determinação da MCU esperada de um produto para um determinado período. Para calcular a MCU esperada, deve-se determinar a MCU para 
Método de determinação da margem de contribuição de produtos com variabilidade de preços e custos diretos unitários: Uma aplicação em uma indústria de produtos plásticos Abraão Freires Saraiva Junior, Maxweel Veras Rodrigues, Reinaldo Pacheco da Costa

cada simulação e aplicar estatística descritiva. Para tal, deve-se fazer o uso de números aleatórios gerados, por exemplo, via algum software específico que, incidindo sobre as distribuições de freqüência extraídas das etapas anteriores, resulta em uma determinada quantidade consumida de recurso (matéria-prima, mão-de-obra e utilidades) e uma correspondente receita unitária de cada produto.

Vale ressaltar que os resultados obtidos seguem a freqüência de ocorrência determinada pelas distribuições de freqüência auferidas e que, para cada simulação, um número aleatório gerado incide tanto nos recursos produtivos, quanto nas receitas unitárias. Multiplicando essas quantidades consumidas, geradas em cada simulação, pelo valor monetário de uma unidade de consumo, consegue-se determinar os gastos unitários para cada produto. A soma desses gastos gerados deve ser dividida por um Índice de Rendimento, cujo cálculo é exposto na equação 2. Este índice tem relação com os custos gerados pela fabricação de produtos não-conformes com a qualidade requerida pelos clientes. A mesma sistemática deve ser aplicada às receitas de vendas desconsiderando os produtos refugados, já que estes não são vendidos.

Em cada sorteio ou geração de número aleatório, a probabilidade de um determinado consumo de um recurso ser obtido é igual à probabilidade ou freqüência relativa que este recurso tem em relação às demais possibilidades. Destaca-se que cada número aleatório, sendo este não-nulo, valora-se entre 0 e 1. Para o cálculo da MCU de cada produto, em cada simulação, faz-se o uso da fórmula apresentada a seguir:

$$
\mathrm{MCU}_{\mathrm{n}}=\mathrm{PV}_{\mathrm{n}}-\left\{\left(\frac{\mathrm{CMD}_{\mathrm{n}}+\mathrm{CMOD}_{\mathrm{n}}+\mathrm{CDU}_{\mathrm{n}}}{\mathrm{IR}}\right)+\left(\mathrm{DVU}_{\mathrm{n}}\right)\right\}
$$

Onde:

$\mathrm{n}$ - número da simulação realizada $(\mathrm{n}=1,2,3, \ldots, \mathrm{k})$

PV - preço de venda

CMD - custo de material direto

CMOD - custo de mão-de-obra direta 
Método de determinação da margem de contribuição de produtos com variabilidade de preços e custos diretos unitários: Uma aplicação em uma indústria de produtos plásticos Abraão Freires Saraiva Junior, Maxweel Veras Rodrigues, Reinaldo Pacheco da Costa

CDU - custo direto de utilidades (energia direta)

DVU - despesas variáveis unitárias

IR - índice de rendimento

A expressão que define o Índice de Rendimento é dada por:

$$
\mathrm{IR}=1-\left(\frac{\mathrm{np}}{\mathrm{nr}}\right)
$$

Onde:

$\mathrm{nr}$ - número médio de produtos refugados por mês

$\mathrm{np}$ - número médio de produtos produzidos por mês

Para o cálculo do preço de venda, em cada simulação, faz-se:

$$
\mathrm{PV}_{\mathrm{n}}=\text { Cot.PV ALEATÓRIO } \mathrm{n}
$$

Onde:

Cot. PV ALEATÓRIOn - valor cotado para o preço de venda relacionado com o número aleatório

incidente no intervalo correspondente ao valor cotado e gerado na n-ésima simulação $\left(0<\mathrm{n}^{\mathrm{O}}\right.$

aleatório $<=1$ )

Para o cálculo de cada custo unitário (CMD, CMOD ou CDU), em cada simulação, utiliza-se a expressão:

$$
\operatorname{CUN}_{\mathrm{n}}=\text { CoUN ALEATÓRIO }_{\mathrm{n}} \times \text { VURC }
$$

Onde:

CUN $n$ - custo unitário do recurso na n-ésima simulação (CMD, CMOD ou CDU) 
Método de determinação da margem de contribuição de produtos com variabilidade de preços e custos diretos unitários: Uma aplicação em uma indústria de produtos plásticos Abraão Freires Saraiva Junior, Maxweel Veras Rodrigues, Reinaldo Pacheco da Costa

CoUN ALEATÓRIO n - valor do consumo unitário de recurso (material direto, mão-deobra direta ou utilidades) relacionado com o número aleatório gerado na n-ésima simulação:

VURC - valor (custo) por unidade de recurso consumido

Para a determinação do valor da despesa variável unitária, em cada simulação, faz-se um cálculo similar ao apresentado na expressão 3, como é mostrado a seguir:

$$
\text { DVU }_{\mathrm{n}}=\text { DVU ALEATÓRIO }
$$

Onde:

DVU $\mathrm{n}$ - despesa variável unitária

DVU ALEATÓRIO n - valor de despesa variável unitária relacionado com o número aleatório gerado na n-ésima simulação

Após a aplicação das simulações, deve-se determinar a MCU esperada de cada produto para o período em análise. Para tal, projetam-se as MCU's apontadas em cada simulação na forma de uma função densidade de probabilidade para a aplicação de estatística descritiva. A estatística utilizada é a média das MCU's. Assim, para efeito deste estudo, o valor da MCU esperada de cada produto pode ser descrito pela expressão 6:

$$
\mathrm{MCU}_{\mathrm{E}}=\frac{\sum_{\mathrm{n}=1}^{\mathrm{k}} \mathrm{MCU}_{\mathrm{n}}}{\mathrm{k}}
$$

Onde:

k - número de simulações realizadas $(\mathrm{k}>100)$

$M C U_{E}$ - Margem de Contribuição Unitária Esperada de cada tipo de produto 
Método de determinação da margem de contribuição de produtos com variabilidade de preços e custos diretos unitários: Uma aplicação em uma indústria de produtos plásticos Abraão Freires Saraiva Junior, Maxweel Veras Rodrigues, Reinaldo Pacheco da Costa

Para a realização das operações matemáticas anteriores, sugere-se o uso do software EXCEL ${ }^{\circledR} 2007$, tanto por este possuir um recurso de geração de números aleatórios, como por ser de fácil acessibilidade.

\section{CARACTERIZAÇÃO DA EMPRESA}

Esta seção apresenta a aplicação do método proposto a partir de dados e informações coletados em uma indústria que atua na fabricação de produtos plásticos através do beneficiamento de material reciclado. Com mais de 30 anos de existência no mercado, a empresa trabalha com máquinas de injeção e de sopro para fabricar artigos variados como baldes, mesas, cadeiras e bacias. Uma pesquisa divulgada pela Associação Brasileira da Indústria do Plástico (ABIPLAST) revelou que, em 2008, o setor de transformação de plásticos, setor este no qual está inserida a indústria em questão, foi responsável pela geração de 314 mil empregos e apresentou um faturamento de cerca de 41 bilhões de reais, o que mostra a sua relevância para a economia do país (ABIPLAST, 2008).

Em um boletim informativo divulgado pelo Compromisso Empresarial para Reciclagem (CEMPRE), consta que é possível economizar até $50 \%$ de energia com o uso de plástico reciclado (CEMPRE, 2002). Este fato, aliado ao baixo custo de coleta desse material devido à baixa remuneração dos chamados "catadores", faz com que o custo do material reciclado seja menor que o custo do plástico virgem. Em contrapartida, a qualidade do primeiro tipo de plástico é inferior à do segundo, principalmente, no que diz respeito à resistência a esforços mecânicos e à uniformidade de processamento. Uma menor resistência a esforços mecânicos tem impacto negativo sobre a qualidade dos produtos (ex: índices de refugo maiores), enquanto que uma menor uniformidade do processo produtivo acarreta em variabilidade no consumo de recursos produtivos (ex: material direto e tempo de mão-de-obra para processar material) e, conseqüentemente, nos custos destes. 
Método de determinação da margem de contribuição de produtos com variabilidade de preços e custos diretos unitários: Uma aplicação em uma indústria de produtos plásticos Abraão Freires Saraiva Junior, Maxweel Veras Rodrigues, Reinaldo Pacheco da Costa

\subsection{Definição do problema}

Para efeito do corrente estudo, considerou-se que os gestores da indústria em questão necessitavam estipular as MCU's dos produtos para o mês de outubro do ano de 2007, para verificar quais destes possuiam as maiores margens individuais em termos econômicos. Vale ressaltar que o estudo aborda uma situação hipotética em que são estabelecidas algumas suposições sobre o tipo de negócio e sobre processo produtivo da empresa em questão, suposições estas que balizam o cenário empresarial criado para a aplicação do método proposto de forma a evitar possíveis distorções na análise. As suposições são destacadas a seguir:

- A empresa fabrica os seus produtos utilizando material reciclado em sete máquinas com características distintas, porém com Tempos de Ciclo iguais;

- Os preços de venda praticados pela empresa são tabelados e negociáveis;

- Todas as máquinas podem produzir qualquer tipo de produto mediante troca de molde/ferramenta;

- As comissões sobre vendas aumentam conforme o preço de venda aplicado;

- A empresa realiza a entrega dos produtos para os clientes.

\subsection{Aplicação do método}

Nesta seção, é apresentado o emprego do método proposto para a projeção da margem de contribuição unitária dos produtos, para um determinado período, de uma indústria de artefatos plásticos. Em cada etapa do método são trabalhados dados relativos à empresa em questão. Com o intuito de reduzir o excesso de informações desta seção, tomou-se como base informações referentes a um dos produtos fabricados.

\subsubsection{Etapa 1 - analisar e projetar gastos unitários}

Para realizar esta etapa, primeiramente, realizou-se um levantamento dos produtos fabricados pela empresa e a composição de cada um deles, como mostra a Tabela 1. 
Método de determinação da margem de contribuição de produtos com variabilidade de preços e custos diretos unitários: Uma aplicação em uma indústria de produtos plásticos Abraão Freires Saraiva Junior, Maxweel Veras Rodrigues, Reinaldo Pacheco da Costa

Tabela 1: Relação de produtos fabricados e materiais componentes

\begin{tabular}{|c|c|c|c|c|c||}
\hline \multirow{2}{*}{$\begin{array}{c}\text { TIPO DE } \\
\text { PRODUTO }\end{array}$} & \multirow{2}{*}{$\begin{array}{c}\text { CÓDIGO } \\
\text { MNEMÔNICO }\end{array}$} & \multicolumn{4}{|c||}{ COMPOSIÇÃO } \\
\cline { 3 - 6 } & & MATERIAL 1: PLÁSTICO & \multicolumn{2}{c||}{ MATERIAL 2: ALÇA METÁLICA } \\
\cline { 3 - 6 } & & DESCRIÇÃO & QDE (Kg) & DESCRIÇÃO & QDE (Kg) \\
\hline BALDE 8L & BD8L & B/B COLOR. REC. & (VARIÁVEL) & AÇO GALV. 3,4 mm & 0,035 \\
\hline BALDE 10L & BD10L & B/B COLOR. REC. & (VARIÁVEL) & AÇO GALV. 3,4 mm & 0,035 \\
\hline BALDE 15L & BD15L & B/B COLOR. REC. & (VARIÁVEL) & AÇO GALV. 3,4 mm & 0,040 \\
\hline BALDE 20L & BD20L & B/B COLOR. REC. & (VARIÁVEL) & AÇO GALV. 4,0 mm & 0,061 \\
\hline BACIA 45L & BC45L & B/B COLOR. REC. & (VARIÁVEL) & - & - \\
\hline BACIA 73L & BC73L & CAD COLOR. REC. & (VARIÁVEL) & - & - \\
\hline CESTO DE LIXO & CLX & B/B COLOR. REC. & (VARIÁVEL) & - & - \\
\hline $\begin{array}{c}\text { BALDE PARA } \\
\text { CONSTRUÇÃO }\end{array}$ & BCON & B/BPRETO REC. & (VARIÁVEL) & \multirow{2}{*}{ AÇO GALV. 4,0 mm } & 0,057 \\
\hline
\end{tabular}

Fonte: Dados da pesquisa.

Como a empresa utiliza plástico reciclado como matéria-prima, dependendo da qualidade desta, há uma variação no consumo de material e no tempo de fabricação de cada produto no decorrer do ano. Com isso, fez-se um levantamento histórico do gasto de MP dos nove meses anteriores ao período de análise. Os gastos foram segmentados ao máximo, com o intuito de se identificar o quanto cada um deles representa em cada item produzido obtendo, assim, uma visão geral dos gastos envolvidos com o negócio. Para efeito do estudo em curso, analisou-se apenas a variação dos gastos diretos unitários, variação esta que foi projetada na forma de distribuições de freqüência para ser trabalhada por meio de simulação. A Tabela 2, referente ao produto $\mathrm{BCON}$, apresenta o histórico de consumo de MP. Vale ressaltar que o levantamento tomou por base amostras de cinco produtos coletadas a cada lote de cem unidades fabricadas e que os dados foram projetados na forma de distribuições de frequência. 
Método de determinação da margem de contribuição de produtos com variabilidade de preços e custos diretos unitários: Uma aplicação em uma indústria de produtos plásticos Abraão Freires Saraiva Junior, Maxweel Veras Rodrigues, Reinaldo Pacheco da Costa

Tabela 2: Distribuição de freqüência de consumo de material plástico do produto BCON

\begin{tabular}{|c|c|c|c|c|c|c|c|c|c|c|c|c|c|}
\hline \multirow{2}{*}{$\begin{array}{c}\text { MÉDIA AMOSTRAL } \\
\text { DE CONSUMO DE } \\
\text { B/B PRETO. REC.(Kg) }\end{array}$} & \multicolumn{9}{|c|}{ FREQÜÊNCIA ABSOLUTA DE CONSUMO DE MATERIAL EM 2007 - BALDE P/ CONSTRUÇÃO } & \multicolumn{4}{|c|}{ CONSOLIDADO (JAN. À SET.) - BALDE P/ CONSTRUÇÃO } \\
\hline & JAN & FEV & MAR & ABR & MAI & JUN & JUL & AGO & SET & $\begin{array}{l}\text { CONSUMO DE B/B } \\
\text { PRETO. REC.(Kg) }\end{array}$ & $\begin{array}{c}\text { FREQÜÊNCIA } \\
\text { ABSOLUTA }\end{array}$ & $\begin{array}{l}\text { FREQUÊNCIA } \\
\text { RELATIVA }\end{array}$ & $\begin{array}{l}\text { FREQUÊNCIA } \\
\text { ACUMULADA }\end{array}$ \\
\hline 0,630 & 200 & 100 & 100 & 200 & 400 & - & 400 & 400 & 300 & 0,630 & 2.100 & $0,52 \%$ & $0,52 \%$ \\
\hline 0,631 & 300 & 100 & - & 100 & 900 & - & 600 & 500 & 800 & 0,631 & 3.300 & $0,82 \%$ & $1,34 \%$ \\
\hline 0,632 & 600 & 300 & 200 & 300 & 1.700 & - & 800 & 800 & 1.300 & 0,632 & 6.000 & $1,49 \%$ & $2,83 \%$ \\
\hline 0,633 & 500 & 500 & 400 & 500 & 2.300 & - & 1.500 & 1.200 & 1.800 & 0,633 & 8.700 & $2,16 \%$ & $4,98 \%$ \\
\hline 0,634 & 900 & 400 & 700 & 700 & 3.200 & 100 & 2.100 & 1.800 & 2.500 & 0,634 & 12.400 & $3,07 \%$ & $8,06 \%$ \\
\hline 0,635 & 1.300 & 900 & 700 & 900 & 3.900 & 500 & 2.800 & 2.400 & 3.900 & 0,635 & 17.300 & $4,29 \%$ & $12,34 \%$ \\
\hline 0,636 & 1.900 & 1.600 & 1.100 & 1.300 & 3.300 & 200 & 3.500 & 3.200 & 5.800 & 0,636 & 21.900 & $5,43 \%$ & $17,77 \%$ \\
\hline 0,637 & 2.600 & 2.300 & 1.500 & 1.600 & 3.100 & 100 & 4.200 & 4.074 & 5.000 & 0,637 & 24.474 & $6,07 \%$ & $23,84 \%$ \\
\hline 0,638 & 3.000 & 3.100 & 1.600 & 1.900 & 2.995 & 600 & 5.100 & 3.900 & 4.800 & 0,638 & 26.995 & $6,69 \%$ & $30,53 \%$ \\
\hline 0,639 & 3.700 & 3.900 & 1.500 & 2.100 & 2.500 & 400 & 4.500 & 3.500 & 4.300 & 0,639 & 26.400 & $6,54 \%$ & $37,07 \%$ \\
\hline 0,640 & 4.500 & 4.700 & 2.100 & 2.600 & 2.100 & 900 & 3.800 & 2.900 & 3.600 & 0,640 & 27.200 & $6,74 \%$ & $43,82 \%$ \\
\hline 0,641 & 5.200 & 4.200 & 2.400 & 2.900 & 1.800 & 1.200 & 3.500 & 3.200 & 3.985 & 0,641 & 28.385 & $7,04 \%$ & $50,85 \%$ \\
\hline 0,642 & 4.600 & 3.900 & 2.889 & 3.400 & 1.700 & 1.400 & 3.000 & 2.500 & 2.800 & 0,642 & 26.189 & $6,49 \%$ & $57,34 \%$ \\
\hline 0,643 & 4.000 & 3.600 & 3.100 & 3.836 & 1.500 & 900 & 2.400 & 2.600 & 2.700 & 0,643 & 24.636 & $6,11 \%$ & $63,45 \%$ \\
\hline 0,644 & 3.200 & 3.700 & 3.500 & 3.700 & 1.400 & 1.600 & 1.800 & 2.400 & 2.500 & 0,644 & 23.800 & $5,90 \%$ & $69,35 \%$ \\
\hline 0,645 & 2.700 & 2.900 & 3.800 & 3.600 & 1.200 & 1.900 & 1.460 & 2.100 & 2.200 & 0,645 & 21.860 & $5,42 \%$ & $74,77 \%$ \\
\hline 0,646 & 1.500 & 2.000 & 4.200 & 3.000 & 800 & 2.300 & 900 & 1.800 & 2.200 & 0,646 & 18.700 & $4,64 \%$ & $79,40 \%$ \\
\hline 0,647 & 1.400 & 1.494 & 4.400 & 2.600 & 500 & 2.000 & 500 & 1.500 & 2.000 & 0,647 & 16.394 & $4,06 \%$ & $83,47 \%$ \\
\hline 0,648 & 1.300 & 1.300 & 3.900 & 2.100 & 600 & 3.200 & 300 & 1.000 & 1.800 & 0,648 & 15.500 & $3,84 \%$ & $87,31 \%$ \\
\hline 0,649 & 700 & 1.300 & 3.600 & 1.500 & 300 & 3.800 & 200 & 700 & 1.300 & 0,649 & 13.400 & $3,32 \%$ & $90,63 \%$ \\
\hline 0,650 & 600 & 600 & 2.900 & 800 & 200 & 4.300 & - & 400 & 1.700 & 0,650 & 11.500 & $2,85 \%$ & $93,48 \%$ \\
\hline 0,651 & 800 & 800 & 1.500 & 400 & - & 4.400 & 100 & 300 & 1.800 & 0,651 & 10.100 & $2,50 \%$ & $95,98 \%$ \\
\hline 0,652 & 698 & 500 & 1.100 & 200 & 100 & 3.500 & 200 & - & 1.300 & 0,652 & 7.598 & $1,88 \%$ & $97,87 \%$ \\
\hline 0,653 & 300 & 300 & 900 & - & - & 2.400 & - & 100 & 900 & 0,653 & 4.900 & $1,21 \%$ & $99,08 \%$ \\
\hline 0,654 & 100 & 100 & 500 & 100 & - & 1.300 & - & - & 500 & 0,654 & 2.600 & $0,64 \%$ & $99,73 \%$ \\
\hline 0,655 & - & 200 & 200 & - & - & 500 & - & - & 200 & 0,655 & 1.100 & $0,27 \%$ & $100,00 \%$ \\
\hline PRODUÇÃO TOTAL & 446.598 & 444.794 & 488.789 & 40.336 & 36.495 & 37.500 & 433.660 & 43.274 & 61.985 & SOMA & 403.431 & $100 \%$ & \\
\hline
\end{tabular}

Fonte: Dados da pesquisa.

Em seguida, foram coletadas informações referentes aos preços de aquisição dos materiais para determinar os custos por quilograma de consumo. Vale destacar que há produtos formados por mais de um componente, como o produto em questão. De cada componente foram retirados os impostos sobre compra de matéria-prima, sendo estes recuperados posteriormente na venda. Assim, calculou-se o custo da matériaprima por produto ou componente, como mostra a Tabela 3. O custo do material é alocado diretamente no cálculo do gasto unitário de cada produto.

Tabela 3: Custo por quilograma de matéria-prima consumida

\begin{tabular}{|c|c|c|c|c|}
\hline MATÉRIA-PRIMA & PREÇO / Kg & ICMS & IPI & CUSTO / $\mathrm{Kg}$ \\
\hline AÇO GALVANIZADO 3,4 mm & $\mathrm{R} \$ 2,94$ & $\mathrm{R} \$ 0,336$ & $\mathrm{R} \$ 0,14$ & $\mathrm{R} \$ 2,464$ \\
\hline AÇO GALVANIZADO 4,0 mm & $\mathrm{R} \$ 2,94$ & $\mathrm{R} \$ 0,336$ & $\mathrm{R} \$ 0,14$ & $\mathrm{R} \$ 2,464$ \\
\hline PLÁSTICO B/B COLORIDO RECICLADO & $\mathrm{R} \$ 1,66$ & - & - & $\mathrm{R} \$ 1,66$ \\
\hline PLÁSTICO B/B PRETO RECICLADO & $\mathrm{R} \$ 1,62$ & - & - & $\mathrm{R} \$ 1,62$ \\
\hline PLÁSTICO CAD COLORIDO RECICLADO & $\mathrm{R} \$ 2,56$ & - & - & $\mathrm{R} \$ 2,56$ \\
\hline
\end{tabular}

Fonte: Dados da pesquisa. 
Método de determinação da margem de contribuição de produtos com variabilidade de preços e custos diretos unitários: Uma aplicação em uma indústria de produtos plásticos Abraão Freires Saraiva Junior, Maxweel Veras Rodrigues, Reinaldo Pacheco da Costa

Para a determinação dos custos unitários de mão-de-obra direta (MOD) foi realizado um procedimento similar ao utilizado na determinação dos custos unitários anteriores. Como os custos unitários de MOD relacionam-se diretamente com o tempo despendido pelos operários em cada produto e que, no caso da empresa em questão, este tempo está limitado à duração do processamento de cada unidade, foi feito um levantamento histórico dos Tempos de Ciclo (TC) no horizonte de nove meses. Para este levantamento, fez-se o uso de amostras de cinco produtos coletadas a cada lote de cem produtos fabricados. Os tempos foram medidos e disponibilizados pelas máquinas injetoras que dispunham de medidores internos. A Tabela 4 apresenta 0 levantamento realizado para o produto BCON. Os dados levantados foram projetados na forma de distribuições de freqüência.

Tabela 4: Frequência absoluta de tempo unitário de processamento do produto BCON

\begin{tabular}{|c|c|c|c|c|c|c|c|c|c|c|c|c|c|}
\hline \multirow{2}{*}{$\begin{array}{l}\text { TEMPO DE CICLO } \\
\text { (segundos) }\end{array}$} & \multicolumn{9}{|c|}{ FREQÜÊNCIA ABSOLUTA DE TEMPO DE CICLO EM 2007 - BALDE P/ CONSTRUÇÃO } & \multicolumn{4}{|c|}{ CONSOLIDADO (JAN. À SET.) - BALDE P/ CONSTRUÇÃO } \\
\hline & JAN & FEV & MAR & $\mathrm{ABR}$ & MAI & JUN & JUL & AGO & SET & \begin{tabular}{c|} 
TEMPO DE CICLO \\
(segundos)
\end{tabular} & $\begin{array}{l}\text { FREQÜÊNCIA } \\
\text { ABSOLUTA }\end{array}$ & $\begin{array}{l}\text { FREQUÊNCIA } \\
\text { RELATIVA }\end{array}$ & $\begin{array}{l}\text { FREQUÊNCIA } \\
\text { ACUMULADA }\end{array}$ \\
\hline 24 & 300 & 200 & - & 200 & - & - & - & - & 400 & 24 & 1.100 & $0,27 \%$ & $0,27 \%$ \\
\hline 25 & 900 & 400 & 700 & 500 & 200 & - & - & - & 1.200 & 25 & 3.900 & $0,97 \%$ & $1,24 \%$ \\
\hline 26 & 1.800 & 900 & 1.100 & 900 & 300 & - & - & - & 2.100 & 26 & 7.100 & $1,76 \%$ & $3,00 \%$ \\
\hline 27 & 2.900 & 1.600 & 1.500 & 1.300 & 400 & - & - & 100 & 3.100 & 27 & 10.900 & $2,70 \%$ & $5,70 \%$ \\
\hline 28 & 3.800 & 2.300 & 2.200 & 1.700 & 800 & - & - & 300 & 4.200 & 28 & 15.300 & $3,79 \%$ & $9,49 \%$ \\
\hline 29 & 5.100 & 3.300 & 2.900 & 1.900 & 1.300 & 300 & 200 & 500 & 5.800 & 29 & 21.300 & $5,28 \%$ & $14,77 \%$ \\
\hline 30 & 6.498 & 3.900 & 3.700 & 2.100 & 1.700 & 100 & 100 & 700 & 5.600 & 30 & 24.398 & $6,05 \%$ & $20,82 \%$ \\
\hline 31 & 5.300 & 4.794 & 4.600 & 2.600 & 2.600 & 500 & 400 & 900 & 5.200 & 31 & 26.894 & $6,67 \%$ & $27,49 \%$ \\
\hline 32 & 4.700 & 4.200 & 5.800 & 2.900 & 3.400 & 400 & 800 & 1.100 & 4.900 & 32 & 28.200 & $6,99 \%$ & $34,48 \%$ \\
\hline 33 & 4.000 & 3.900 & 4.900 & 3.400 & 4.100 & 900 & 1.000 & 1.300 & 4.200 & 33 & 27.700 & $6,87 \%$ & $41,34 \%$ \\
\hline 34 & 3.200 & 3.600 & 4.100 & 3.900 & 3.795 & 1.200 & 1.600 & 1.700 & 3.900 & 34 & 26.995 & $6,69 \%$ & $48,03 \%$ \\
\hline 35 & 2.700 & 3.700 & 3.889 & 3.700 & 3.400 & 1.400 & 2.400 & 2.200 & 2.885 & 35 & 26.274 & $6,51 \%$ & $54,55 \%$ \\
\hline 36 & 1.500 & 2.900 & 3.500 & 3.600 & 3.000 & 1.700 & 2.800 & 2.900 & 3.200 & 36 & 25.100 & $6,22 \%$ & $60,77 \%$ \\
\hline 37 & 1.400 & 2.400 & 3.000 & 3.000 & 2.700 & 1.600 & 3.500 & 3.500 & 2.900 & 37 & 24.000 & $5,95 \%$ & $66,72 \%$ \\
\hline 38 & 900 & 2.100 & 2.400 & 2.600 & 2.100 & 1.900 & 4.200 & 4.400 & 2.500 & 38 & 23.100 & $5,73 \%$ & $72,44 \%$ \\
\hline 39 & 700 & 2.600 & 1.800 & 2.100 & 1.900 & 2.300 & 5.100 & 3.900 & 1.900 & 39 & 22.300 & $5,53 \%$ & $77,97 \%$ \\
\hline 40 & 600 & 900 & 1.100 & 1.536 & 1.700 & 2.000 & 4.500 & 3.574 & 2.100 & 40 & 18.010 & $4,46 \%$ & $82,44 \%$ \\
\hline 41 & 300 & 600 & 800 & 1.100 & 1.400 & 3.200 & 3.800 & 3.300 & 1.800 & 41 & 16.300 & $4,04 \%$ & $86,48 \%$ \\
\hline 42 & - & 300 & 400 & 600 & 900 & 3.800 & 3.500 & 3.200 & 1.400 & 42 & 14.100 & $3,50 \%$ & $89,97 \%$ \\
\hline 43 & - & 200 & 300 & 300 & 500 & 4.300 & 3.260 & 2.800 & 1.100 & 43 & 12.760 & $3,16 \%$ & $93,13 \%$ \\
\hline 44 & - & - & - & 200 & 200 & 4.600 & 2.200 & 2.400 & 800 & 44 & 10.400 & $2,58 \%$ & $95,71 \%$ \\
\hline 45 & - & - & 100 & 200 & & 3.500 & 1.800 & 2.100 & 400 & 45 & 8.100 & $2,01 \%$ & $97,72 \%$ \\
\hline 46 & - & - & - & - & 100 & 2.100 & 1.200 & 1.400 & 200 & 46 & 5.000 & $1,24 \%$ & $98,96 \%$ \\
\hline 47 & - & - & - & - & - & 1.200 & 900 & 700 & 100 & 47 & 2.900 & $0,72 \%$ & $99,68 \%$ \\
\hline 48 & - & - & - & - & - & 500 & 400 & 300 & 100 & 48 & 1.300 & $0,32 \%$ & $100,00 \%$ \\
\hline$\overline{\text { RODUÇÃO TOTAL }}$ & 46.598 & 44.794 & 48.789 & 40.336 & 36.495 & 37.500 & 43.660 & 43.274 & 61.985 & SOMA & 403.431 & $100 \%$ & \\
\hline
\end{tabular}

Fonte: Dados da pesquisa.

Para a determinação do custo da mão-de-obra diretamente envolvida com a fabricação dos produtos, foram analisados os gastos com: salário nominal, adicional 
Método de determinação da margem de contribuição de produtos com variabilidade de preços e custos diretos unitários: Uma aplicação em uma indústria de produtos plásticos Abraão Freires Saraiva Junior, Maxweel Veras Rodrigues, Reinaldo Pacheco da Costa

noturno, encargos sociais, férias, décimo terceiro salário, vale-transporte, vale-refeição e equipamentos de proteção individual. A partir desses dados, fez-se um consolidado por função, com seu gasto total. Em seguida, calculou-se o custo da mão-de-obra por hora e por segundo da função Auxiliar de Fabricação, função esta diretamente relacionada com a fabricação dos produtos. Para isso, obteve-se o somatório dos salários e encargos de cada funcionário e calculou-se a média mensal de custos de mão-de-obra direta. Posteriormente, para determinar o custo total de mão-de-obra direta, multiplicou-se o custo médio pela quantidade de Auxiliares de Fabricação existentes na fábrica. $O$ valor total encontrado foi dividido pela carga horária mensal total de trabalho para a determinação do custo por hora. Finalmente, dividiu-se o custo por hora por 3.600 para encontrar o custo de mão-de-obra direta por segundo de trabalho. O custo por segundo de MOD encontrado foi de $R \$ 0,00101$. O custo por segundo de MOD foi utilizado no cálculo do custo unitário de MOD de cada produto ou componente, valor que participa diretamente na determinação da MCU. A Tabela 5 mostra o cálculo para os componentes dos produtos em estudo:

Tabela 5: Custo de MOD para cada componente dos produtos

\begin{tabular}{||c|c|c|c|c|}
\hline ITEM / PRODUTO & $\begin{array}{c}\text { TEMPO DE } \\
\text { CICLO } \\
\text { (segundos) }\end{array}$ & $\begin{array}{c}\text { CUSTO / } \\
\text { SEGUNDO DE } \\
\text { MOD }\end{array}$ & $\begin{array}{c}\text { NECESSIDADE DE } \\
\text { OPERÁRIOS P/ } \\
\text { PRODUÇÃO }\end{array}$ & $\begin{array}{c}\text { CUSTO DE } \\
\text { MOD / ITEM }\end{array}$ \\
\hline ALÇA METÁLICA 3,4 mm / BD8L & 2,7 & 0,00101 & 1 & 0,002727 \\
\hline ALÇA METÁLICA 3,4 mm / BD10L & 2,7 & 0,00101 & 1 & 0,002727 \\
\hline ALÇA METÁLICA 3,4 mm / BD15L & 3,1 & 0,00101 & 1 & 0,003131 \\
\hline ALÇA METÁLICA 4,0 mm / BD20L & 8,0 & 0,00101 & 1 & 0,00808 \\
\hline ALÇA METÁLICA 4,0 mm / BCON & 8,0 & 0,00101 & 1 & 0,00808 \\
\hline
\end{tabular}

Fonte: Dados da Pesquisa.

Para a determinação dos custos relacionados com a energia diretamente consumida pelas máquinas do setor produtivo, foi feito um levantamento histórico dos gastos totais com energia na empresa. Em seguida, verificou-se que uma parte do consumo energético não se relacionava diretamente à fabricação dos produtos, como no caso da iluminação, computadores da administração central, ar-condicionado, entre outros. Assim, foi retirado da conta de energia total da empresa, desconsiderando os 
Método de determinação da margem de contribuição de produtos com variabilidade de preços e custos diretos unitários: Uma aplicação em uma indústria de produtos plásticos Abraão Freires Saraiva Junior, Maxweel Veras Rodrigues, Reinaldo Pacheco da Costa

impostos, apenas o que foi consumido diretamente no processo produtivo, considerando o restante como consumo indireto. O valor encontrado foi de $R \$ 0,19551$ por KWh.

Para encontrar o valor do consumo energético de cada máquina diretamente relacionada com a fabricação dos produtos, foram realizadas mensurações a partir de medidores eletrônicos e observações nos manuais dos fabricantes. Os valores encontrados foram multiplicados pelo custo por KWh previamente calculado, o que resultou no custo de energia por hora de operação de cada máquina. Por motivo de adequação à unidade de tempo utilizada no corrente estudo, o segundo, dividiu-se os valores encontrados por 3.600 .

Das máquinas utilizadas na produção, verificou-se que a ALÇA 1 operava apenas na fabricação das alças metálicas de $3,4 \mathrm{~mm}$, enquanto que a máquina ALÇA 2 fabricava somente as alças de $4,0 \mathrm{~mm}$. O produto BCON poderia ser fabricado em qualquer uma das máquinas dos modelos INJ AB, INJ MN e INJ XY. Assim, de posse da quantidade existente de cada modelo e considerando que o tempo de ciclo não era afetado pela máquina escolhida para a produção, projetaram-se as probabilidades de cada uma das máquinas serem selecionadas para produzir um produto através de distribuições de freqüência, como mostra a Tabela 6.

Tabela 6: Custo de energia por segundo de utilização das máquinas e probabilidade de seleção para produção

\begin{tabular}{|c|c|c|c|c|c|c|}
\hline MÁQUINA & $\begin{array}{c}\text { CONSUMO DE } \\
\text { ENERGIA (KWh) }\end{array}$ & $\begin{array}{c}\text { CUSTO / } \\
\text { KWh }\end{array}$ & $\begin{array}{c}\text { CUSTO DE ENERGIA / } \\
\text { HORA-MÁQUINA }\end{array}$ & $\begin{array}{c}\text { CUSTO DE ENERGIA / } \\
\text { SEG.-MÁQUINA }\end{array}$ & \multirow{3}{*}{$\begin{array}{l}\text { FREQÜÊNCIA } \\
\text { RELATIVA }\end{array}$} & \multirow{3}{*}{$\begin{array}{l}\text { FREQÜÊNCIA } \\
\text { ACUMULADA }\end{array}$} \\
\hline ALÇA 01 & 3,04 & 0,19551 & 0,5943504 & 0,00016510 & & \\
\hline ALÇA 02 & 1,52 & 0,19551 & 0,2971752 & 0,00008255 & & \\
\hline INJ AB 01 & 34,20 & \begin{tabular}{|l|}
0,19551 \\
\end{tabular} & 6,686442 & \multirow{2}{*}{0,00185735} & \multirow{2}{*}{$40 \%$} & \multirow{2}{*}{$40 \%$} \\
\hline INJ AB 02 & 34,20 & 0,19551 & 6,686442 & & & \\
\hline INJ MN 01 & 30,40 & 0,19551 & 5,943504 & 0,00165097 & $20 \%$ & $60 \%$ \\
\hline INJ XY 01 & 32,30 & 0,19551 & 6,314973 & \multirow{2}{*}{0,00175416} & \multirow{2}{*}{$40 \%$} & \multirow{2}{*}{$100 \%$} \\
\hline INJ XY 02 & 32,30 & 0,19551 & 6,314973 & & & \\
\hline & & & & TOTAL & $100 \%$ & \\
\hline
\end{tabular}

Fonte: Dados da Pesquisa. 
Método de determinação da margem de contribuição de produtos com variabilidade de preços e custos diretos unitários: Uma aplicação em uma indústria de produtos plásticos Abraão Freires Saraiva Junior, Maxweel Veras Rodrigues, Reinaldo Pacheco da Costa

As despesas variáveis consideradas pela empresa em estudo são referentes aos gastos com comissão sobre vendas e com a entrega de cada produto. Verificou-se que a alíquota da comissão do vendedor incidente sobre o preço de venda praticado era variável e tabelada. Quanto maior a cotação do preço, maior a alíquota da comissão. Desta forma, os vendedores eram motivados a vender os produtos pelos maiores preços possíveis. Pelo fato de a empresa realizar a distribuição dos produtos para lojas de atacado e de varejo a partir de uma frota própria de veículos, as despesas relacionadas com a entrega dos produtos foram determinadas para cada produto. Para tal, foram analisados os gastos relacionados com pneus utilizados, combustível, diárias dos motoristas e ajudantes, entre outros. Esses gastos foram considerados como despesas variáveis, sendo influenciados pelo volume de venda dos produtos.

Para a determinação da despesa variável unitária de entrega de cada tipo de produto, fez-se o uso de dados históricos relativos ao total gasto com os itens acima citados e de informações a respeito da área ocupada por cada tipo de produto no compartimento de carga dos veículos. Vale ressaltar que os valores cotados são aproximados. A Tabela 7 apresenta as alíquotas de comissão de vendas os valores de despesa de entrega.

Tabela 7: Despesas variáveis de comissão sobre vendas e de entrega por produto

\begin{tabular}{|c|c|c|c|}
\hline $\begin{array}{l}\text { COTAÇÃO } \\
\text { DO PREÇO }\end{array}$ & $\begin{array}{l}\text { COMISSÃO SOBRE O } \\
\text { PREÇO DE VENDA }\end{array}$ & PRODUTO & $\begin{array}{l}\text { DESPESA VARIÁVEL } \\
\text { DE ENTREGA }\end{array}$ \\
\hline \multirow{2}{*}{ P1 } & \multirow{2}{*}{$0,4 \%$} & BD8L & $\mathrm{R} \$ 0,0434$ \\
\hline & & BD10L & $\mathrm{R} \$ 0,0443$ \\
\hline \multirow{2}{*}{ P2 } & \multirow{2}{*}{$0,6 \%$} & BD15L & $\mathrm{R} \$ 0,0586$ \\
\hline & & BD20L & $\mathrm{R} \$ 0,0703$ \\
\hline \multirow{2}{*}{ P3 } & \multirow{2}{*}{$0,8 \%$} & BC45L & $\mathrm{R} \$ 0,0712$ \\
\hline & & BC73L & $\mathrm{R} \$ 0,1184$ \\
\hline \multirow{2}{*}{ P4 } & \multirow{2}{*}{$1,0 \%$} & CLX & $\mathrm{R} \$ 0,0665$ \\
\hline & & BCON & $\mathrm{R} \$ 0,0649$ \\
\hline
\end{tabular}

Fonte: Dados da pesquisa. 
Método de determinação da margem de contribuição de produtos com variabilidade de preços e custos diretos unitários: Uma aplicação em uma indústria de produtos plásticos Abraão Freires Saraiva Junior, Maxweel Veras Rodrigues, Reinaldo Pacheco da Costa

As informações obtidas nesta etapa, aliadas à projeção das receitas unitárias de vendas que será apresentada na seção seguinte, foram utilizadas diretamente na determinação da MCU de cada produto.

\subsubsection{Etapa 2 - analisar e projetar receitas unitárias}

Após levantamento junto ao Setor Comercial da empresa, verificou-se que a precificação era realizada de forma tabelada. Para cada produto era utilizada uma tabela com quatro cotações de preço (do menor para o maior): P1, P2, P3 e P4. De acordo com o poder de barganha do cliente, o vendedor estava autorizado a oferecer um desconto até o valor mínimo de P1. De posse dos preços praticados para a venda de cada produto, um estudo histórico foi realizado para determinar a freqüência de incidência de cada uma das cotações, como mostra a Tabela 8 , relativo ao produto BCON.

Tabela 8: Preços praticados na venda do produto BCON com a incidência histórica de cada cotação

\begin{tabular}{|c|c|c|c||}
\hline \multicolumn{5}{|c|}{ BALDE PARA CONSTRUÇÃO } \\
\hline COTAÇÃO & PREÇO DE VENDA & $\begin{array}{c}\text { FREQÜÊNCIA } \\
\text { RELATIVA }\end{array}$ & $\begin{array}{c}\text { FREQÜÊNCIA } \\
\text { ACUMULADA }\end{array}$ \\
\hline $\mathrm{P} 1$ & $\mathrm{R} \$ 3,70$ & $15 \%$ & $15 \%$ \\
\hline $\mathrm{P} 2$ & $\mathrm{R} \$ 3,80$ & $25 \%$ & $40 \%$ \\
\hline $\mathrm{P} 3$ & $\mathrm{R} \$ 3,90$ & $40 \%$ & $80 \%$ \\
\hline $\mathrm{P} 4$ & $\mathrm{R} \$ 4,00$ & $20 \%$ & $100 \%$ \\
\hline \multicolumn{5}{|r}{} \\
\hline
\end{tabular}

Fonte: Dados da pesquisa.

Os valores e as distribuições de freqüências encontradas, aliados à simulação de Monte Carlo, foram utilizados na determinação da MCU esperada para o mês de outubro de 2007 de cada produto. O cálculo da MCU esperada é abordado na etapa a seguir. 
Método de determinação da margem de contribuição de produtos com variabilidade de preços e custos diretos unitários: Uma aplicação em uma indústria de produtos plásticos Abraão Freires Saraiva Junior, Maxweel Veras Rodrigues, Reinaldo Pacheco da Costa

\subsubsection{Etapa 3 - aplicar simulação e determinar a margem de contribuição unitária esperada do produto}

De posse dos custos por unidade de recursos produtivos (matéria-prima, mãode-obra e energia elétrica) diretamente consumidos, dos preços de venda praticados e das distribuições de freqüência dos consumos unitários de recursos e das cotações de preço por produto, determinou-se a Margem de Contribuição Unitária Esperada para o mês de outubro de 2007 para cada tipo de produto. Para tal, fez-se o uso do método de simulação de Monte Carlo com a geração de números aleatórios que incidiram sobre as distribuições de freqüência determinadas para cada consumo de recurso, despesa variável e cotação de preço de venda.

A utilização da simulação de Monte Carlo para determinação da MCUE deu-se da seguinte forma: geraram-se números aleatórios não-nulo entre 0 e 1, que foram remetidos, com base nas distribuições de freqüência estabelecidas, a um valor correspondente de consumo de matéria-prima, tempo de ciclo, custo energético por segundo de operação de máquina e preço de venda cotado. As distribuições de freqüência relativa apontaram as probabilidades de ocorrência de cada valor. As distribuições de freqüência absoluta serviram como base para a definição dos intervalos, entre 0 e 1, que se relacionavam aos números aleatórios gerados. Este procedimento foi replicado 500.000 vezes para a consecução de uma amostra representativa da realidade empresarial modelada. O quadro 10 apresenta uma aplicação de três simulações para o produto BCON, seguindo as expressões 3 , 4 e 5 apresentadas na seção 4.3.

Tabela 9: Aplicação de simulação de Monte Carlo ao produto BCON

\begin{tabular}{|c|c|c|c|c|c|c|c|c|}
\hline \multirow{2}{*}{ No SIMULAÇÃO $^{\text {NÚMERO }}$} & $\begin{array}{c}\text { CONSUMO B/B } \\
\text { ALEATÓRIO }\end{array}$ & $\begin{array}{c}\text { NÚMERO } \\
\text { PRETO. REC. (Kg) }\end{array}$ & $\begin{array}{c}\text { TEMPO DE } \\
\text { ALEATÓRIO }\end{array}$ & $\begin{array}{c}\text { NÚMERO } \\
\text { CICLO (seg.) }\end{array}$ & $\begin{array}{c}\text { CUSTO DE ENERGIORIO } \\
\text { seg. MÁQUINA }\end{array}$ & $\begin{array}{c}\text { NÚMERO } \\
\text { ALEATÓRIO }\end{array}$ & $\begin{array}{c}\text { RECEITA } \\
\text { UNITÁRIA }\end{array}$ \\
\hline 1 & 0,543 & 0,642 & 0,152 & 30 & 0,874 & 0,00185735 & 0,446 & 3,90 \\
\hline 2 & 0,321 & 0,639 & 0,946 & 44 & 0,121 & 0,00175416 & 0,479 & 3,90 \\
\hline 3 & 0,682 & 0,644 & 0,537 & 35 & 0,497 & 0,00165097 & 0,281 & 3,80 \\
\hline
\end{tabular}

Fonte: Dados da pesquisa. 
Método de determinação da margem de contribuição de produtos com variabilidade de preços e custos diretos unitários: Uma aplicação em uma indústria de produtos plásticos Abraão Freires Saraiva Junior, Maxweel Veras Rodrigues, Reinaldo Pacheco da Costa

Os valores encontrados relativos ao consumo unitário de matéria-prima foram multiplicados, em cada simulação, pelo custo por quilograma do material plástico utilizado em cada tipo de produto. Assim, conseguiu-se determinar o custo de material direto de cada produto fabricado, em cada simulação. Os tempos de ciclo encontrados foram multiplicados pelo custo de mão-de-obra direta por segundo de trabalho e pelo custo de energia por segundo de operação de máquina para a determinação do custo de MOD e da energia direta de cada tipo de produto, respectivamente. O somatório dos três custos unitários calculados foi dividido pelo Índice de Rendimento, como sugere a expressão 2. Para o cálculo do $\mathrm{IR}$, foi realizado um levantamento histórico da quantidade total produzida (3.397.223 produtos) nos nove meses anteriores ao período em analise. Em seguida, levantou-se o número total de unidades produzidas que não atenderam às necessidades dos clientes, expressas através de especificações de projeto (101.905 produtos). Desta forma, obteve-se um IR de 0,97. Assim, em cada simulação, a soma dos custos diretos de MP, de MOD e de energia foi dividida pelo valor do IR calculado, o que inflacionou, levemente, o valor dos custos unitários de cada produto. Esse valor adicionado ao custo unitário direto representa os gastos incorridos na fabricação dos produtos que não atendiam às especificações técnicas do projeto.

Os custos determinados em cada simulação, inflacionados pelo IR, foram somados aos custos unitários relacionados com a fabricação dos componentes/acessórios (alça metálica). Esta soma foi aplicada, exclusivamente, aos produtos BCON, BD8L, BD10L, BD15L e BD20L pelo fato dos demais produtos não possuirem componentes/acessórios. Finalmente, para o cálculo do gasto total unitário de cada produto, o valor da soma anterior foi adicionado ao valor das despesas variáveis unitárias. Tomando como base a expressão 1 do método proposto, os valores de gasto total unitário foram confrontados com as receitas unitárias para a determinação, em cada simulação, das MCU's dos produtos. A Tabela 10 apresenta, para o produto BCON, as quinze primeiras MCU's obtidas com as simulações. Ressalta-se que as 500.000 simulações realizadas para cada tipo de produto foram executadas no software EXCEL® 2007. Os números aleatórios gerados não aparecem 
Método de determinação da margem de contribuição de produtos com variabilidade de preços e custos diretos unitários: Uma aplicação em uma indústria de produtos plásticos Abraão Freires Saraiva Junior, Maxweel Veras Rodrigues, Reinaldo Pacheco da Costa

na Tabela 10, pois estes foram inseridos diretamente nas fórmulas de cálculo de cada item, quando aplicável.

Tabela 10: Determinação das MCU's do produto BCON em cada simulação

\begin{tabular}{|c|c|c|c|c|c|c|c|c|c|c|c|c|c|c|c|}
\hline \multicolumn{16}{|c|}{ DETERMINAÇĀO DA MCU - BALDE PARA CONSTRUÇĀO } \\
\hline $\begin{array}{c}N^{2} \\
\text { SIMU- } \\
\text { LAÇĀO }\end{array}$ & $\begin{array}{c}\text { CONSUMO } \\
\text { B/B } \\
\text { PRETO. } \\
\text { REC. }(\mathrm{Kg}) \\
\end{array}$ & \begin{tabular}{|c|} 
CUSTO / \\
Kg DE B/B \\
PRETO. \\
REC. \\
\end{tabular} & \begin{tabular}{|c|} 
TEMPO \\
DE \\
CICLO \\
(seg.) \\
\end{tabular} & $\begin{array}{c}\text { CUSTO } \\
\text { / seg. } \\
\text { DE MOD }\end{array}$ & $\begin{array}{c}\text { CUSTO DE } \\
\text { ENERGIA / } \\
\text { seg. MÁQUINA }\end{array}$ & \begin{tabular}{|c|} 
CONSUMO \\
AÇO GALV. \\
$\begin{array}{c}4,0 \mathrm{~mm} \\
(\mathrm{Kg})\end{array}$ \\
\end{tabular} & \begin{tabular}{|c|} 
CUSTO / \\
Kg AÇO \\
GALV. 4,0 \\
$\mathrm{~mm}$
\end{tabular} & $\begin{array}{c}\text { TEMPO DE } \\
\text { CICLO (seg.) } \\
\text { ALÇA METÁL. }\end{array}$ & $\begin{array}{c}\text { CUSTO } \\
\text { DE MOD } \\
\text { / ALÇA }\end{array}$ & $\begin{array}{c}\text { CUSTO DE } \\
\text { ENERGIA / } \\
\text { seg. ALÇA 02 }\end{array}$ & $\begin{array}{c}\text { DESPESA } \\
\text { DE } \\
\text { ENTREGA }\end{array}$ & $\begin{array}{r}\text { RECEITA } \\
\text { UNITÁRIA }\end{array}$ & $\begin{array}{l}\text { COMISSÃO } \\
\text { SOBRE } \\
\text { VENDA }\end{array}$ & $\begin{array}{c}\text { GASTO } \\
\text { UNITÁRIO } \\
\text { TOTAL }\end{array}$ & MCU \\
\hline 1 & 0,644 & 1,62 & 31 & 0,001 & 0,00165097 & 0,057 & 2,464 & 8,0 & 0,00808 & 0,000082549 & 0,0649 & 3,90 & 0,0312 & 1,405876 & 2,49412 \\
\hline 2 & 0,641 & 1,62 & 43 & 0,001 & 0,00185735 & 0,057 & 2,464 & 8,0 & 0,00808 & 0,000082549 & 0,0649 & 3,90 & 0,0312 & 1,442934 & 2,45707 \\
\hline 3 & & & 35 & & & & 2,464 & 8,0 & 0,00808 & 0,000082549 & 0,0649 & 3,90 & 0,0312 & 1,413892 & 2,48611 \\
\hline 4 & 0,646 & 1,62 & 40 & 0,001 & 0,00185735 & 0,057 & 2,464 & 8,0 & 0,00808 & 0,000082549 & 0,0649 & 3,70 & 0,0148 & 1,426016 & 2,27398 \\
\hline 5 & 0,639 & 1,62 & 31 & 0,001 & 0,00165097 & 0,057 & 2,464 & 8,0 & 0,00808 & 0,000082549 & 0,0649 & 4,00 & 0,04 & 1,406326 & 2,59367 \\
\hline 6 & 0,644 & & 44 & & 0,00185735 & & 2,464 & 8,0 & 0,00808 & 0,000082549 & 0,0649 & 4,00 & 0,04 & & 2,54030 \\
\hline 7 & 0,638 & 1,62 & 31 & 0,001 & 0,00185735 & 0,057 & 2,464 & 8,0 & 0,00808 & 0,000082549 & 0,0649 & 4,00 & 0,04 & 1,411251 & 2,58875 \\
\hline 8 & 0,647 & 1,62 & 34 & 0,001 & 0,00185735 & 0,057 & 2,464 & 8,0 & 0,00808 & 0,000082549 & 0,0649 & 3,80 & 0,0228 & 1,41795 & 2,38205 \\
\hline 9 & 0,633 & 1,62 & 38 & 0,001 & 0,00175416 & 0,057 & 2,464 & 8,0 & 0,00808 & 0,000082549 & 0,0649 & 3,80 & 0,0228 & 1,40235 & 2,39765 \\
\hline 10 & 0,637 & 1,62 & 41 & 0,001 & 0,00185735 & 0,057 & 2,464 & 8,0 & 0,00808 & 0,000082549 & 0,0649 & 3,80 & 0,0228 & 1,421941 & 2,37806 \\
\hline 11 & 0,636 & 1,62 & 39 & 0,001 & 0,00175416 & 0,057 & 2,464 & 8,0 & 0,00808 & 0,000082549 & 0,0649 & 4,00 & 0,04 & 1,42741 & 2,57259 \\
\hline 12 & 0,642 & 1,62 & 33 & 0,001 & 0,00165097 & 0,057 & 2,464 & 8,0 & 0,00808 & 0,000082549 & 0,0649 & 3,80 & 0,0228 & 1,399623 & 2,40038 \\
\hline 13 & 0,648 & 1,62 & 37 & 0,001 & 0,00185735 & 0,057 & 2,464 & 8,0 & \begin{tabular}{|l|}
0,00808 \\
\end{tabular} & \begin{tabular}{|l|}
0,000082549 \\
\end{tabular} & 0,0649 & 3,70 & 0,0148 & 1,420488 & 2,27951 \\
\hline 14 & 0,647 & 1,62 & 33 & 0,001 & 0,00185735 & 0,057 & 2,464 & 8,0 & 0,00808 & 0,000082549 & 0,0649 & 3,80 & 0,0228 & 1,414994 & 2,38501 \\
\hline 15 & 0,641 & 1,62 & 28 & 0,001 & 0,00175416 & 0,057 & 2,464 & 8,0 & 0,00808 & 0,000082549 & 0,0649 & 3,90 & 0,0312 & 1,395615 & 2,50439 \\
\hline
\end{tabular}

Fonte: Dados da pesquisa.

As MCU's geradas foram projetadas na forma de uma função densidade de probabilidade. A partir dessa função, determinou-se a Margem de Contribuição Unitária Esperada para o mês de outubro, de cada tipo de produto. Para tal, foi aplicada estatística descritiva, de acordo com a expressão 6 , na forma de média através da utilização do software MINITAB® 15.0. A figura 4 mostra os valores da MCUE para outubro de 2007 de todos os produtos, bem como o comportamento das MCU's geradas do produto BCON: 
Método de determinação da margem de contribuição de produtos com variabilidade de preços e custos diretos unitários: Uma aplicação em uma indústria de produtos plásticos Abraão Freires Saraiva Junior, Maxweel Veras Rodrigues, Reinaldo Pacheco da Costa

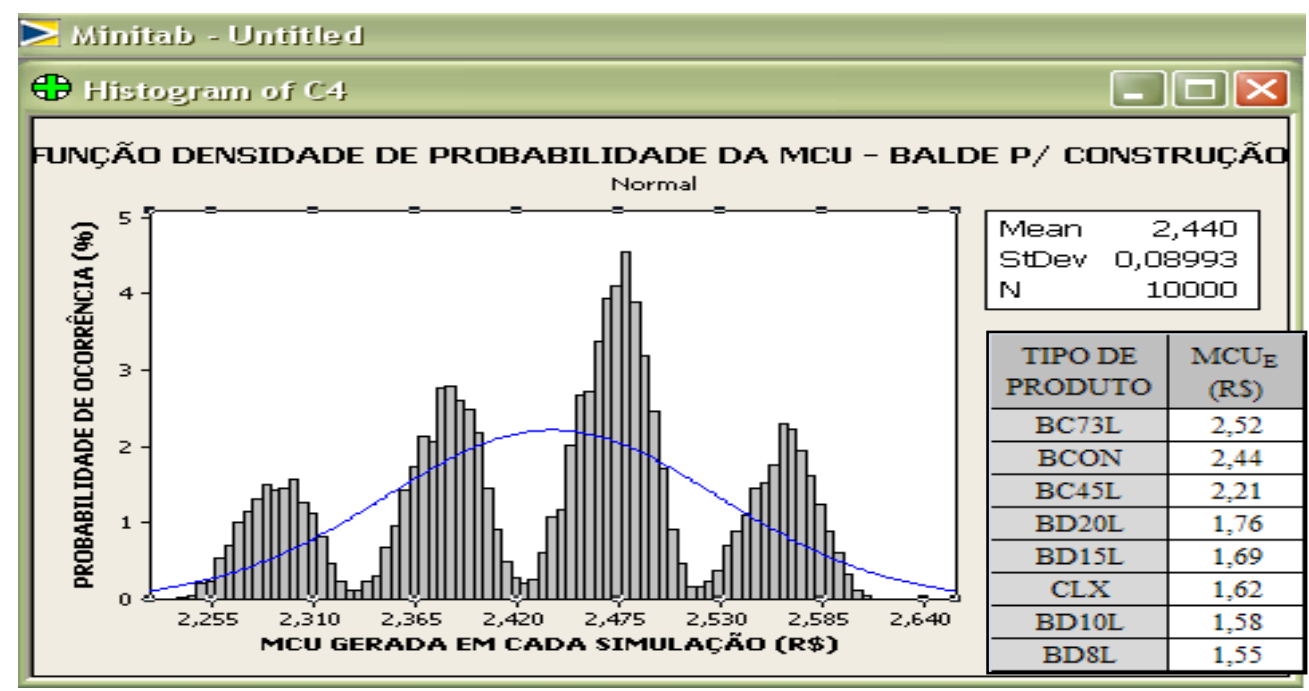

Figura 4: Determinação da $M C U_{E}$ do produto BCON a partir do software MINITAB ${ }^{\circledR} 15.0$ Fonte: Dados da pesquisa.

\section{ANÁLISE DOS RESULTADOS}

Pelos resultados projetados, todos os produtos possuem MCUE positiva e contribuem para a cobertura de gastos fixos e para a consequente geração de lucro à empresa. Os produtos BC73L, BCON e BC45L apresentam MCUE com superioridade destacada em relação aos demais cinco produtos. A diferença obtida entre a maior e a menor MCUE foi de 62,58\% (BC73L e BD8L).

Vale ressaltar, ainda, que as margens obtidas poderiam ser maiores caso a empresa conseguisse uma maior estabilização do seu processo produtivo. Para tal, poder-se-ia diminuir o tempo despendido na fabricação de produtos defeituosos a partir da adoção de programas de melhoria da qualidade. Além disso, os gestores da empresa poderiam trabalhar, junto aos fornecedores de matéria-prima, para a consecução de plástico reciclado de melhor qualidade, o que acarretaria em uma redução da variabilidade do processo produtivo tanto em termos de consumo de material, como também de tempo de fabricação de cada produto. 
Método de determinação da margem de contribuição de produtos com variabilidade de preços e custos diretos unitários: Uma aplicação em uma indústria de produtos plásticos Abraão Freires Saraiva Junior, Maxweel Veras Rodrigues, Reinaldo Pacheco da Costa

\section{CONCLUSÃO}

Este estudo apresentou uma sistemática para a margem de contribuição unitária dos produtos (esperada para um determinado período) a partir da união de conceitos e técnicas provindos da Contabilidade Gerencial e da Pesquisa Operacional. Especificamente, considerando que a empresa opera com uma grande variabilidade de gastos e receitas unitárias, realizou-se a aplicação do método de simulação de Monte Carlo e de estatística descritiva para a determinação dos produtos que possuiam os maiores desempenhos econômicos em termos unitários.

O conhecimento detalhado da estrutura de custos da empresa foi imprescindível para averiguar se os produtos contribuíam para a alavancagem do resultado econômico da empresa e em quanto. A utilização da simulação de Monte Carlo foi necessária para o tratamento, caso a caso, dos gastos e dos preços de venda unitários dos produtos, já que a simples adoção de uma média aritmética para os valores não se adequava à realidade de acentuada variação.

Convém observar que um acompanhamento contínuo dos gastos deve ser realizado pelos gestores para que ações corretivas imediatas possam ser tomadas no momento em que ocorrerem variações acentuadas. Fazer essa análise dos gastos requer disciplina e determinação, além de demandar amplo esforço, porém, proporciona informações que ajudam os gestores a tomar decisões mais precisas.

Finalmente, espera-se que este estudo contribua como referencial teórico para outros estudos que envolvam o tratamento da variabilidade de custos diretos e receitas unitárias dentro do campo da gestão econômica de organizações.

\section{REFERÊNCIAS}

ABIPLAST. (2008). Perfil da indústria brasileira de transformação de material plástico. Disponível em: http://www.abiplast.org.br/upload/File/Perfil2008/PERFIL_2008.zip. Acesso em: 15/out/2009.

ASSEF, R. (2005). Gerência de preços como ferramenta de marketing. (2 ed.). Rio de Janeiro: Campus, $224 \mathrm{p}$. 
Método de determinação da margem de contribuição de produtos com variabilidade de preços e custos diretos unitários: Uma aplicação em uma indústria de produtos plásticos Abraão Freires Saraiva Junior, Maxweel Veras Rodrigues, Reinaldo Pacheco da Costa

BANKS, J.; CARSON, J. e NELSON, B. 1996. Discrete-event system simulation. New Jersey: Prentice Hall, 548 p.

BERNARDI, L. A. 2004. Manual de formação de preços: políticas, estratégias e fundamentos. $3^{\underline{a}}$ ed. São Paulo: Atlas, 280 p.

BORSHCHEV, A. e FILIPPOV, A. (2004). From system dynamics and discrete event to practical agent based modeling: reasons, techniques, tools. In: XXII International Conference of the System Dynamics Society. Anais... Oxford, England: Keble College

BRUNI, A. L. (2006). Administração de custos, preços e lucros. São Paulo: Atlas, 388 p.

BUFFA, E. S. (1973). Modern production management. (4 ed.). New York: John Willey \& Sons, $718 \mathrm{p}$.

CEMPRE.c (2002). Negócios e oportunidades. CEMPRE informa, oㅜ66. Disponível em: Http://cempre.tecnologia.ws/cempre_informa.php?lnk=ci_2002-1112_inter.php. Acesso em: 06/abril/09.

COSTA, R. P. (1998). Proposta de modelo e implementação de um sistema de apoio a decisão em pequenas empresas. São Paulo, SP. (Tese de Doutorado). Escola Politécnica da Universidade de São Paulo - POLI USP, 198 p.

DAVIS, M. M.; AQUILANO, N. J. e CHASE, R. B. (1999). Fundamentals of operations management. (3 ed.). Boston: Irwin/McGraw-Hill, 600 p.

FORRESTER, J. W. (1961). Industrial dynamics. Cambridge: MIT Press, 464 p.

FOSTER, B. P. e BAXENDALE, S. J. (2008). The absorption vs. direct costing debate. Cost Management, 22(4): 40-48.

GARRISON, R. H.; NOREEN, E. W. e BREWER, P. C. (2006). Managerial accounting. (11 ed.). New York: McGraw Hill, 880 p.

GENTLE, J. (2003). Random number generation and Monte Carlo methods. (2 ed.). New York: Springer, $381 \mathrm{p}$.

GIL, A. C. (2002). Como elaborar projetos de pesquisa. (4 ed.). São Paulo: Atlas, 242 p.

GUERREIRO, R. (2006). Gestão do Lucro. São Paulo: Atlas, 152 p.

HILLIER, F. S. e LIEBERMAN, G. J. (2005). Introduction to operations research. 8th ed. New York: McGraw Hill, 1080 p. 
Método de determinação da margem de contribuição de produtos com variabilidade de preços e custos diretos unitários: Uma aplicação em uma indústria de produtos plásticos Abraão Freires Saraiva Junior, Maxweel Veras Rodrigues, Reinaldo Pacheco da Costa

LAW, A. M. e KELTON, W. D. (2000). Simulation Modeling and Analysis. (3 ed.). New York: McGraw-Hill, $760 \mathrm{p}$.

LEONE, G. S. (2000). Curso de contabilidade de custos. (2 ed.). São Paulo: Atlas, 222 p.

LUSTOSA, P. R. B.; PONTE, V. M. R. e DOMINAS, W. R. (2004). Simulação. In: CORRAR, L. J. e THEÓPHILO, C. R. (Org.). Pesquisa operacional para decisão em contabilidade e administração. São Paulo: Atlas, 489 p.

MARCONI, M. A. e LAKATOS, E. M. (2008). Fundamentos de metodologia científica. (6 ed.). São Paulo: Atlas, 315 p.

MARTINS, E. (2006). Contabilidade de custos. (9 ed.). São Paulo: Atlas, 370 p.

METROPOLIS, N. (1987). The beginning of the Monte Carlo method. Disponível em: http://library.lanl.gov/la-pubs/00326866.pdf. Acesso em: 21/out/2009.

METROPOLIS, N. e ULAM, S. (1949). The Monte Carlo method. Journal of the American Statistical Association, 44(247): 335-341.

PADOVEZE, C. L. (2006). Curso Básico gerencial de custos. (2 ed.). São Paulo: Pioneira Thomson Learning, $410 \mathrm{p}$.

PIDD, M. (1998). Modelagem empresarial: ferramentas para tomada de decisão. Porto Alegre: Bookman, $316 \mathrm{p}$.

PRADO, D. (2004). Teoria das filas e da simulação. (2 ed.). Minas Gerais: INDG, 126p.

SAKURADA, N. e MIYAKE, D. (2009). Aplicação de simuladores de eventos discretos no processo de modelagem de sistemas de operações de serviços. Gestão e Produção, 16(1): 25-43.

SHAMBLIN, J. E. e STEVENS, G. T. (1974). Operations research: a fundamental approach. New York: McGraw-Hill, 404 p.

WINSTON, W. L. (1994). Operations research: applications and algorithms. (3 ed.). Belmont: Duxbury Press, 1318 p.

YIN, R. K. (2005). Estudo de caso: planejamento e método. (3 ed.). Porto Alegre: Bookman, $212 \mathrm{p}$. 
Método de determinação da margem de contribuição de produtos com variabilidade de preços e custos diretos unitários: Uma aplicação em uma indústria de produtos plásticos Abraão Freires Saraiva Junior, Maxweel Veras Rodrigues, Reinaldo Pacheco da Costa

Data de Submissão: 22/07/2009

Data de Aceite: 18/11/2009 